\title{
ARGENTINOS À BRASILEIRA. A CIRCULAÇÃO DE ANTROPÓLOGOS ARGENTINOS PELO MUSEU NACIONAL (PPGAS-MN/UFRJ)
}

\author{
Nicolás José Isola ${ }^{1}$ \\ ${ }^{1}$ Universidade Estadual de Campinas, Faculdade de Educação, Campinas/SP,
} Brasil

\section{Introdução'}

A mobilidade de estudantes não é um fenômeno social novo (Verger 1991; Karady 1998). A sociologia do campo intelectual tem se dedicado a descrever as trocas internacionais produzidas nos diversos espaços de reunião intelectual, procurando entender as dinâmicas de coesão, associação e institucionalização dos diferentes espaços transnacionais da cultura (Coser 1968; Bauman 1997).

Intelectuais e acadêmicos têm valorizado as viagens como estratégia de distinção por meio do acesso ao prestígio social (Siméant 2015) no que diz respeito à capacidade ética de compreender espaços e mundos diversos (Wagner \& Réau 2015).

Porém, a internacionalização não se dá por um mero acaso. A vida intelectual e científica não é espontaneamente internacional (Bourdieu 2002). A mesma noção de internacionalização é um objeto em disputa (Bourdieu 2001; Beigel \& Sabea 2014).

As diferentes tradições científicas nacionais se afiançaram - e se afiançam - por meio de ações simbólicas que estimularam a manutenção e a reprodução de uma "comunidade imaginada" (Anderson 1993), especialmente centrada na unidade territorial e simbólica (Bourdieu 2006). Em face dessa unidade, que muitas vezes opera como fechamento ao exterior, para os processos de internacionalização acontecerem são necessárias condições sociais particulares (Bourdieu 2002).

A crescente mobilidade estudantil nas últimas décadas (OECD 2001; veja-se também ISU 2018 para os últimos anos) apresenta características 
vinculadas às qualidades dos distintos sistemas de ensino superior, e aos desiguais financiamento, profissionalização e institucionalização dos programas de pós-graduação (PPG), o que implica um processo heterogêneo e assimétrico na disputa pelo acesso ao espaço internacional.

Torna-se preciso indagar acerca das condições e das forças que contribuem para a configuração particular das diferentes modalidades de internacionalização, procurando abranger uma maior compreensão dos fluxos - formais e informais - que se produzem entre países distintos. Desnaturalizar os fluxos internacionais implica estudar os fatos peculiares que promoveram a formação de circuitos de circulação internacional e confluíram para ela (Heilbron et al. 2008).

Para interrogar essas trocas científicas é preciso considerá-las nas suas particularidades através do tempo, ponderando a história das redes e dos vínculos (afetivos, institucionais e políticos) que foram mobilizados. Em algumas ocasiões, essas redes são objetivadas, por exemplo, por meio da assinatura de instrumentos institucionais, como acordos e convênios que podem ser vistos como pontos de passagem entre fronteiras nacionais, e terminam gerando parcerias e fluxos muito além das expectativas e das intenções originais daqueles atores que, no início, motivaram as primeiras conexões.

Esse conjunto de elementos leva ao questionamento das condições sociais que tornam possível a circulação internacional (Bourdieu 2002), isto é, a interrogação sobre as razões e os condicionantes dos fluxos que, como destaca Hannerz (1997:12), "têm direções" e geram "uma reorganização da cultura no espaço".

Existem trabalhos que avançaram na descrição dos fenômenos de internacionalização do campo científico brasileiro ligados fortemente à circulação de estudantes brasileiros pelos países centrais (Almeida et al. 2004; Garcia 2005; Muñoz \& Garcia 2004-2005). Também há trabalhos que aprofundaram o conhecimento sobre as históricas missões científicas internacionais no campo da Antropologia Social no Brasil (Corrêa 1987; Cardoso de Oliveira 1992; Garcia 2009a, 2009b).

Tendo em conta essas conceitualizações, este trabalho descreve os laços históricos de um circuito de circulação sul-sul da "Antropologia periférica" (Cardoso de Oliveira 2006): a circulação de antropólogos argentinos pelo Programa de Pós-graduação em Antropologia Social do Museu Nacional (PPGAS-MN).

Algumas das conexões existentes entre antropólogos brasileiros e argentinos foram mencionadas em estudos prévios (cf. Ratier \& Guebel 2004; Heredia 2009; Leite Lopes 2013), porém não existem trabalhos que 
tenham examinado especificamente a institucionalização dessas trocas entre o PPGAS-MN e a Universidade de Buenos Aires (UBA).

A partir da documentação disponível nos arquivos do PPGAS-MN e dos relatos de alguns dos atores envolvidos, propõe-se reconstruir as trocas que levaram à institucionalização de um convênio que permitiu a circulação de estudantes argentinos por esse Programa brasileiro. O texto apresenta, na primeira parte, a estrutura do convênio e delineia as características e o conteúdo do instrumento de avaliação que era administrado na UBA e que permitia o ingresso no mestrado ou no doutorado do PPGAS-MN. Em seguida, a partir de uma exposição das complexas condições institucionais que apresentava o campo da Antropologia na Argentina até a década de 1980, analisa-se a percepção dos jovens estudantes argentinos que vieram ao Brasil no âmbito desse convênio sobre suas experiências e sobre as dificuldades que encontraram para se adaptar a essa cultura institucional que estava num estágio de maior profissionalização e internacionalização do que aquela de seu país de origem.

Assim, este estudo procura acrescentar ao debate sobre a internacionalização do espaço acadêmico o conhecimento sobre um caso de circulação sul-sul que permita abrir novas perguntas sobre um assunto ainda pouco estudado: a conformação e a consolidação de fluxos estáveis no nível regional.

\section{Os primeiros laços de antropólogos argentinos com o PPGAS-MN}

"A ciência é internacional", assim começa um dos parágrafos da exposição de Donald Pierson (1987:90) sobre a sua trajetória na Antropologia no Brasil. Esta afirmação é facilmente notada quando se examina o caso brasileiro.

A criação de instituições públicas como a Universidade de São Paulo (1934) e, especialmente, a Faculdade de Filosofia, Ciências e Letras convocou diferentes missões estrangeiras e pesquisadores provenientes da Europa e dos Estados Unidos (Limongi 1989).

Nas décadas seguintes, o Estado brasileiro desenvolveu um sistema de apoio e promoção às atividades de pesquisa criando instituições científicas e agências para a formação de uma base nacional de pesquisadores. Este foi o caso do Conselho Nacional de Desenvolvimento Científico e Tecnológico (CNPq), criado no ano 1949, e da Campanha de Aperfeiçoamento do Pessoal de Nível Superior (Capes) (Martins 2005), que teve como referência os Estados Unidos (Parecer no 977/65). Estas criações estiveram ligadas 
à circulação de estudantes brasileiros pelos centros internacionais mais prestigiosos (Canêdo \& Garcia 2004-2005), assim como à circulação de pesquisadores estrangeiros pelo Brasil (Schwartzman 1991; Miceli 1995). Tal mobilidade também foi fomentada por agências privadas, como a Ford Foundation (Miceli 1993).

O caso da Antropologia moderna brasileira não é a exceção. Como mostram vários estudos, a circulação internacional foi uma das características centrais do processo que levou ao seu surgimento e consolidação (Corrêa 1987; Garcia 2009a). Na década de 1930, por exemplo, os franceses Claude Lévi-Strauss e Roger Bastide participaram dos primeiros anos da USP; o inglês Radcliffe-Brown (Thomaz \& Cabral 2011) e o norte-americano Donald Pierson contribuíram com a Escola de Sociologia e Política de São Paulo (Pierson 1987); o projeto da Unesco, nos anos 1950, sobre relações raciais no Brasil permitiu que jovens brasileiros se iniciassem na disciplina; e a lista poderia continuar (Willems 1987; Fry 2004).

Essa internacionalização foi uma característica do Museu Nacional (MN), ainda antes da criação do PPGAS-MN. Diferentes pesquisadores estrangeiros procuraram estabelecer laços com o MN para a realização de pesquisas e/ou trabalhos de campo nas ciências naturais e antropológicas (Cardoso de Oliveira 1992). Dali partiam para realizar expedições e viagens (Leite Lopes 1992; Pace 2014).

No marco dessa circulação de pesquisadores, o Museu Nacional foi se transformando em um espaço institucional de relevância para a disciplina, como mostra o fato de que a primeira Reunião Brasileira de Antropologia tenha tido lugar ali em novembro de 1953, e que desse mesmo local, posteriormente, surgiria a Associação Brasileira de Antropologia (Corrêa 2003).

A partir de 1960, cursos de especialização em Teoria de Pesquisa em Antropologia Social e Cultural foram organizados por Roberto Cardoso de Oliveira e Luiz de Castro Faria. Roque de Barros Laraia, Roberto DaMatta, Alcinda Ramos, Edson Diniz, Hortência Caminha e Odília Benvenucci participaram da primeira turma daquele curso (Laraia 2010). Desses primeiros cursos participaram vários professores estrangeiros, situando o Programa "sob a égide do intercâmbio com outros países" (Cardoso de Oliveira 1992:53).

Além de David Maybury-Lewis, entre esses professores se encontravam os norte-americanos Richard Adams, Shelton Davis, Henry Selby; o mexicano Guillermo Bonfil Batalla; e o sociólogo argentino Jorge Graciarena (Velho 2012; Cardoso de Oliveira 1992).

Em maio de 1963, David Maybury-Lewis (Universidade de Harvard) e Roberto Cardoso de Oliveira (MN) assinaram um acordo entre as duas 
instituições que permitiu a realização do "Harvard Central Brazil Research Project" dirigido por David Maybury-Lewis para estudos sistemáticos dos grupos Gê (Garcia 2009a). ${ }^{2}$

Naquela equipe binacional, deu-se uma fusão estável entre os diversos capitais culturais e sociais dos pesquisadores que provinham dos Estados Unidos e a recepção, a reconfiguração e os aportes que os pesquisadores brasileiros realizavam (Garcia 2009a). Como fruto desses intercâmbios, estudantes como Roque de Barros Laraia e Roberto DaMatta puderam continuar seus estudos em Harvard.

É no contexto desse conjunto de trocas, cursos e projetos de pesquisa que deve ser considerada a criação do programa de mestrado do PPGAS-MN em 1968, ${ }^{3}$ associado ao projeto "Estudo Comparativo do Desenvolvimento Regional" idealizado por Roberto Cardoso e David Maybury-Lewis.

Cinco meses depois da criação do PPGAS-MN, foi editado o Ato Institucional n. 5 que possibilitou a perseguição de estudantes e professores militantes (Garcia 2009a). O PPGAS-MN, uma instituição pequena e com disciplinas como etnologia ou arqueologia, consideradas pouco politizadas, ficou afastado das perseguições militares e converteu-se num guarda-chuva institucional que abrigou, nos anos seguintes, os novos cientistas sociais brasileiros e argentinos cujo acesso a outros espaços institucionais estava bloqueado. ${ }^{4}$

O primeiro grupo de argentinos chegou ao Brasil em agosto de 1970. Era composto por alunos da Universidade Nacional de La Plata (UNLP), alguns deles encaminhados por Alberto Rex González, ${ }^{5}$ e outros por Richard Adams, que tinha oferecido um curso ali mesmo (Heredia 2009). Eles eram: Roberto Ringuelet e Luis Maria Gatti, da Universidade Nacional de Córdoba; e Omar Gancedo, presente em um semestre. Em 1971, viajaram Martin Ibañez Novion, também da UNLP, e Beatriz Heredia, da Universidade Nacional de Córdoba. Richard Adams era consultor da Fundação Ford e todos eles tiveram bolsas concedidas por essa Fundação (Heredia 2009). Naqueles anos, "tudo acontecia como se a Antropologia da Universidade de Harvard e da Fundação Ford representaram 'aliados alternativos' com a perda de peso social e político dos círculos da esquerda nacionalista" (Garcia 2009b:65). ${ }^{6}$

Três argentinos completaram seu mestrado no PPGAS: Ringuelet ${ }^{7}$, Ibañez Novion e Beatriz Alasia de Heredia. Luis Maria Gatti, Roberto Ringuelet e Beatriz Heredia, casada com outro antropólogo que também passaria pelo PPGAS-MN, Osvaldo Heredia, tinham sido convidados por Moacir Palmeira, professor do PPGAS-MN, graças às suas conexões com a Fundação Ford, na condição de coordenador na região Nordeste do projeto "Estudo Comparativo de Desenvolvimento Regional". Num depoimento fortemente ligado à sua trajetória, Beatriz Heredia (2009:167) assinala: 
O projeto forneceu as bases para a constituição e a consolidação do grupo de estudos sobre campesinato, dirigido por Moacir Palmeira e formado por Lygia Sigaud, então já mestre pelo PPGAS, e os alunos Afrânio R. Garcia, Marie France Garcia, José Sérgio Leite Lopes, Roberto Ringuelet, Luis Maria Gatti, Vera Etchenique e eu mesma.

Com efeito, as dissertações de mestrado de Beatriz Heredia ${ }^{8}$ e de Roberto Ringuelet foram desenvolvidas no marco desse trabalho de campo, sob a orientação de Moacir Palmeira.

Esse grupo voltou para a Argentina e procurou propagar tudo aquilo que tinha aprendido no trabalho conjunto, que representava uma inovação para a Argentina, onde a Antropologia Social tinha um papel muito reduzido (cf. Heredia 2009).

Anos mais tarde, com o golpe militar de 1976, esses antropólogos tiveram de sair da Argentina. Beatriz Heredia voltou para o PPGAS-MN e se incorporou ao projeto "Emprego e Mudança Socioeconômica no Nordeste", dirigido por Moacir Palmeira; Ringuelet começou a lecionar na Universidade Federal de Rio Grande do Norte; e Gatti foi trabalhar no México com Bonfil Batalha, de quem tinha sido aluno no PPGAS. Moacir Palmeira relata o processo que começaria naqueles anos:

Houve uma sequência de argentinos, um número razoável de pessoas que acabaram ficando por aqui. E para a gente essa presença foi interessante. Rompeu um pouco esquemas que eram, como em todo país, esquemas nacionais muito rígidos. E tivemos figuras ótimas (Entrevista com Moacir Palmeira).

De todos os argentinos que passaram entre os anos 1960 e 1970 pelo PPGAS-MN, Beatriz Heredia foi uma das pessoas que mais incentivaram os laços entre os antropólogos brasileiros e argentinos.

\section{As condições da internacionalização da Antropologia argentina até a década de 1980}

Os fluxos científicos internacionais devem ser compreendidos tendo em conta as condições e os contextos encontrados tanto nos países que operam como receptores quanto nos países de origem dos estudantes. Essas diversas condições estruturais (estabilidade sociopolítica; existência de financiamento, bolsas e mercado de trabalho acadêmico; promoção da internacionalização etc.) fazem parte dos mecanismos sociais objetivos que promovem - ou não - processos de circulação internacional (Bourdieu 2002). 
O encontro entre os antropólogos argentinos e brasileiros se deu em condições muito especiais. Os dois países estavam sob ditaduras, porém mostravam caraterísticas diferentes: no Brasil havia o surgimento da Antropologia moderna e das pós-graduações, enquanto na Argentina, a Antropologia atravessava uma grande crise. Por isso, para entender o impacto internacionalizador posterior, é necessário ter uma concisa perspectiva da situação do campo disciplinar da Antropologia na Argentina até aqueles anos 80, especialmente em torno da sua abertura e receptividade em face da internacionalização. Caso contrário, ficará difícil ter uma impressão acabada do que o PPGAS-MN começou a simbolizar para os professores e os estudantes argentinos.

A graduação em Antropologia tanto na UBA quanto na UNLP foram criadas em 1958. Nas primeiras décadas da institucionalização da Antropologia como disciplina científica na Argentina, ela contou com uma baixa influência direta de antropólogos reconhecidos dos países centrais (Ratier \& Ringuelet 1997; Ratier \& Guebel 2004), preponderando a influência de alguns atores italianos e austríacos fortemente focados na etnologia, de fraco diálogo com a antropologia norte-americana, britânica e francesa da época, e de características fascistas (cf. Guber 2008; Silla 2012; Perazzi 2014; Neufeld et al. 2015). Algo muito diferente do acontecido no início da institucionalização da disciplina brasileira com personagens como Lévi-Strauss, Bastide, Braudel, entre muitos outros (Corrêa 1987; Garcia 2009b). ${ }^{9}$

No período de institucionalização da Antropologia, nas décadas de 60 e 70, existia nas Ciências Sociais e Humanas uma resistência muito arraigada em relação aos marcos teóricos e metodológicos "colonialistas" provenientes dos Estados Unidos (Bartolomé 2007). ${ }^{10}$

A defesa dessa fronteira interna jazia no ativismo político de uma ideologia transformadora e, às vezes, armada que, em algumas ocasiões, abandonava toda a pretensão de autonomia científica e declarava que seu principal objetivo era modificar a realidade (Vessuri 1973; Ratier 1983). A este respeito é sugestiva uma lembrança narrada por Roberto Cardoso de Oliveira:

Eu lembro que, na mesma época, Richard Adams [naquele tempo consultor da Fundação Ford] vinha à Argentina, e foi rejeitado. Não foi aceito por ser norte-americano. Entretanto, nós o aproveitamos muito bem [...]. Nós estávamos mais interessados em receber a sua experiência acadêmica que a política (Guebel et al. 1996:99).

A rejeição a Adams explicita bem o clima da época no espaço científico argentino, tanto quanto o aproveitamento estratégico por parte dos antropólogos brasileiros explicita parte da cultura disciplinar do país. 
A agressiva intervenção policial na UBA em julho de 1966, no marco do golpe de Estado daquele ano, gerou renúncias massivas de professores (como o caso de Hugo Ratier, ${ }^{11}$ que anos mais tarde se exilaria no Brasil, e Esther Hermitte, doutorada na Universidade de Chicago no ano 1964) como rechaço à interrupção da ordem constitucional e o desrespeito da autonomia universitária. Dez anos mais tarde, com o golpe de Estado de 1976, a universidade ficaria ainda mais dizimada, com a demissão de docentes e a perseguição e o desaparecimento de professores e estudantes, muitos dos quais tiveram que optar pelo exílio interno e externo (cf. Neufeld et al. 2015).

Dois casos permitem considerar aqueles anos de suspeitas cruzadas. No primeiro, o arqueólogo Alberto Rex González, doutor pela Universidade de Colúmbia (EUA), tentou atrair para a Argentina a implantação de uma pós-graduação em Antropologia Social promovida e financiada pela Fundação Ford (Bartolomé 2007). Porém, a proximidade da iniciativa com a revelação do Projeto "Camelot", patrocinado pelo Departamento da Defesa dos EUA, que procurava "ordenar" a produção de conhecimento em ciências sociais no Sul, aumentou as suspeitas de que a Antropologia poderia prestar-se a atividades de contrainsurgência arquitetadas pelo imperialismo. Ao mesmo tempo, essa Fundação era acusada de servir a interesses estrangeiros e espúrios. Aquela pós-graduação acabou, assim, não sendo implementada.

No segundo caso, Esther Hermitte, que tinha um projeto de pesquisa no Estado do Chaco, na Argentina, foi acusada por grupos de esquerda, sem provas, de estar por trás da instalação de antropólogos da CIA na Argentina (Guber 2014).

Ao lembrar desse período, no estudo de Bartolomé (2007:17) se descreve o conjunto de desconfianças que, na sua perspectiva, atravessavam e paralisavam a disciplina:

A Antropologia Social dificilmente acharia sua pista acadêmica em tal clima: suspeitas dos setores de esquerda ligadas ao financiamento externo; suspeitas do governo, setores sindicais e simpatizantes pela proximidade extrema com a população; e suspeitas da guerrilha pelo atraso nos resultados provenientes da pesquisa. Neste fogo cruzado, o desenvolvimento acadêmico e, particularmente, o socioantropológico não era apenas impraticável, mas também inútil.

Outros autores parecem concordar com essa visão. Segundo Ratier e Guebel (2004:152), o fraco poder de refração diante dos discursos ideológicos e da débil autonomia do espaço científico em face do espaço político "cortava os pés da disciplina: não havia onde se parar". 
O localismo nacionalista impactava também o modo tendencioso como se abordavam certos autores. Uma perspectiva politizada e criticista instigava, inclusive, a evitar alguns textos.

Numa reflexão sobre aquele período, o professor Ratier, que havia sido diretor do Departamento de Ciências Antropológicas da Faculdade de Filosofia e Letras da UBA em 1973, e que posteriormente fora chefe do Departamento de Sociologia e Antropologia, e coordenador da Pós-graduação da Universidade Federal de Paraíba, no Brasil, comenta:

O respeito pelos autores e a procura por colocar o autor no seu tempo e contexto foram coisas que aqui [na Argentina], pelo menos em nossa formação, não apareceram. Aqui nós enterramos a antropologia funcionalista na porta da Faculdade, os alunos foram e a enterraram. ${ }^{12}$ Então não era mais lida, porque eles "são os caras que não servem". No Brasil não acontece o mesmo. Isto para mim faz a diferença (Entrevista com Hugo Ratier).

Na Argentina, entre 1973 e 1976, o curso de Ciências Antropológicas da UBA teve três diferentes programas de estudos, e na Universidade Nacional de Rosario, o curso foi fechado entre 1976 e 1984 (Bartolomé 2007). As descontinuidades impediam os avanços. No Brasil, ainda sob a ditadura militar, foi possível erigir e consolidar PPGs de qualidade ligados a universidades norte-americanas.

Segundo a visão de alguns pesquisadores, os frutos desses complexos e diferentes processos históricos entre ambos os países podem ser vistos ainda hoje. Nas palavras de Mauricio Boivin, um dos protagonistas centrais da assinatura do convênio PPGAS-MN/UBA nos anos 80 e atual diretor do Departamento de Ciências Antropológicas da UBA: "A Antropologia brasileira tem algo a dizer de sua própria realidade, a Amazônia e todo esse tipo de questões têm sido uma linguagem de poder muito mais clara que a antropologia argentina. Nós somos mais localistas" (Entrevista com Mauricio Boivin).

A tensão que destaca Boivin excede estes dois espaços nacionais. Trata-se de uma oposição recorrente nas práticas da Antropologia realizadas em países periféricos, onde o posicionamento escolhido potencializa uma ou outra perspectiva. Essa tensão chega, inclusive, a operar em alguns casos como estruturadora do espaço discursivo da disciplina, posicionando os âmbitos de enunciação dos diversos atores (cf. Velho 2003).

Na Argentina, durante os anos 80, que foram anos de reconstrução de espaços destruídos pelo regime militar, houve uma forte crise econômica com hiperinflação, greves gerais dos sindicatos, perda do poder aquisitivo dos salários etc. Nesse contexto, a construção do sistema de pós-graduação ainda demoraria a acontecer. 
Naquela década, um mestrado foi criado na Faculdade Latino-americana de Ciências Sociais (Flacso) no ano de 1982. Fechado em 1985, foi reaberto quase vinte anos depois, em 2003 (Bartolomé 2007). Na Universidade Nacional de Misiones a pós-graduação foi criada em 1996 (Bartolomé 2007).

Nos anos 80, os antropólogos e a Antropologia Social argentina se constituíam num grupo geracional fragmentado, com uma memória descontínua e um sentido histórico e um futuro ainda não compartidos (Guber \& Visacovsky 1998).

A descontinuidade e a baixa institucionalidade se mantiveram até os anos 90. Ainda assim houve eventos, como as reuniões da ABA e coesões institucionais importantíssimas, como a primeira Reunião de Antropologia do Mercosul - RAM (1995), ${ }^{13}$ que fortaleceram o diálogo e as colaborações entre os antropólogos da região. Programas de Pós-graduação de prestígio, como os da Universidade Nacional de Córdoba e da Universidade Nacional de General San Martín, ambos com uma forte marca da Antropologia Social brasileira, foram criados apenas em 2001.

Tendo em conta a baixa profissionalização e o reduzido financiamento do espaço da Antropologia na Argentina nos anos 80, devem ser considerados os laços institucionais e os processos de circulação internacional que serão descritos a seguir.

\section{Um encontro que estreitou os laços}

Em 1985 teve lugar na cidade de Olavarría, ${ }^{14}$ Estado de Buenos Aires, o I Congreso Argentino y Latinoamericano de Antropología Rural (Calaar), organizado por Hugo Ratier, com o apoio da UBA e da UNLP, entre outras instituições. Este Congresso pode ser considerado o primeiro evento da Antropologia Social na democracia. Pesquisadores que trabalhavam no Brasil, entre eles Beatriz Heredia, Salete Barbosa Cavalcanti, Gisélia Franco Potengi, Gustavo Lins Ribeiro e Guillermo Ruben, foram convidados por Hugo Ratier, que havia realizado o curso completo de doutorado no PPGAS-MN no início dos anos 80 e que, já na Argentina, introduziu precocemente autores brasileiros, como DaMatta e Leite Lopes, e ajudou no fortalecimento dos laços que tinha em função de sua circulação pelo Brasil. ${ }^{15}$

Um ano depois, nos dias 6, 7 e 8 de agosto de 1986, realizou-se em Buenos Aires o II Congresso Argentino de Antropologia Social. Professores do PPGAS-MN foram convidados por Beatriz Heredia. Entre os brasileiros que participaram se encontravam José Sérgio Leite Lopes, Giralda Seyferth, Otávio e Gilberto Velho, Afrânio Garcia, Moacir Palmeira, Lygia Sigaud, João 
Pacheco de Oliveira Filho e Gustavo Lins Ribeiro. Também participaram professores mexicanos convidados por Neiburg, que cursou sua graduação no México, assim como professores argentinos que residiam no exterior, como Hebe Vessuri, Santiago Bilbao, Rita Segato, entre outros (Guber 2010).

Em sua perspectiva pessoal, Beatriz Heredia considera que aquele Congresso foi um dinamizador dos fluxos entre os antropólogos de ambos os países:

A tradição da presença de alunos latino-americanos no PPGAS, pensada e concretizada por Roberto Cardoso de Oliveira [que começou nos anos 70], foi retomada anos depois, mais precisamente em agosto de 1986, por ocasião de um Congresso de Antropologia - o primeiro após a retomada da democracia na Argentina - por iniciativa de um grupo de colegas do MN, sob a coordenação de José Sérgio Leite Lopes. Dele participei como um dos proponentes e como elemento de ligação entre o decano Dr. Rodriguez Bustamante e seu secretário acadêmico, o antropólogo Mauricio Boivin, quando foi assinado um convênio entre o PPGAS-MN e a Faculdade de Filosofia e Ciências Sociais da UBA, que daria início, desta vez sem interrupções, a um novo fluxo de alunos argentinos em direção ao PPGAS (2009:169).

Havia muita efervescência no campo da Antropologia na Argentina no contexto da retomada da democracia. Entrevistado, o professor Mauricio Boivin, então secretário da Faculdade de Filosofia e Letras da UBA e posteriormente chefe da Seção de Antropologia Social do Departamento de Ciências Antropológicas da UBA, assinala: "Durante a ditadura militar só ingressavam 35 alunos por ano no Departamento de Antropologia da UBA. Em 1984, os ingressantes no Departamento fizeram dobrar a quantidade total de alunos inscritos" (Entrevista com Mauricio Boivin).

A Antropologia não era uma exceção, todas as Ciências Sociais e Humanas haviam sido perseguidas pelo governo militar. Durante aqueles anos, muitos acadêmicos destas áreas tinham organizado grupos de estudo fora da universidade, que se encontrava dizimada e sob intervenção.

Diversos atores, que eram professores e estudantes naquele tempo, consideram que o Congresso de 1986 foi importantíssimo. Roberto Ringuelet, destaca que "devido ao seu tamanho e à posição central da UBA, foi uma celebração paradigmática do começo de uma nova etapa. Para isso, contribuiu a presença de estrangeiros, especialmente de latino-americanos, como os professores do PPGAS-MN" (Entrevista com Roberto Ringuelet), tanto que, desde a perspectiva de Federico Neiburg, essa nova etapa foi vivida como o "lançamento de uma nova Antropologia na Argentina" (Entrevista com Federico Neiburg). 
Os objetivos daquele Congresso foram:

- I. Integrar os profissionais da Antropologia Social do país e da América Latina num encontro que permita uma visão atualizada dos problemas ligados à teoria e à prática da especialidade.

- II. Analisar comparativamente problemáticas similares em temáticas diversas.

- $\quad$ III. Promover a difusão da atividade antropológica em nível nacional.

Nesses poucos dias, em torno do Congresso, entre almoços e jantares, houve uma sinergia especial entre os pesquisadores brasileiros e os professores e jovens estudantes argentinos: temas de interesse comum, perspectivas metodológicas e enfoques teóricos faziam parte das conversas. Nas palavras de Moacir Palmeira: "essa ida ao Congresso foi uma festa. Foi muito legal" (Entrevista com Moacir Palmeira).

Do ponto de vista do professor argentino Gustavo Sorá, que anos depois realizaria seu mestrado e seu doutorado no PPGAS-MN,

naquele Congresso os brasileiros se deslumbraram pela cultura política, pela efervescência. Eu sei que ficaram muito impactados e retomaram antigas alianças. O certo é que ali se começa a pensar o convênio para enviar estudantes argentinos para formar-se lá, porque aqui não havia nenhuma pós-graduação: "Enviemos a estudar fora para depois implantar o sistema aqui" (Entrevista com Gustavo Sorá).

Essa camaradagem entre brasileiros e argentinos estava ligada, por um lado, a uma vizinhança cultural que excede este estudo (Lovisolo 2000; Grimson \& Semán 2006; Pousadela 2007; Palermo 2015); pelo outro, a enfoques teórico-metodológicos comuns entre alguns professores do PPGAS-MN e grupos de pesquisa da Argentina - onde Boivin e Ratier eram referências - que realizavam trabalho de campo e recuperavam alguns autores da Antropologia Clássica (assunto que é objeto de outro artigo em curso). Com efeito, não por acaso, os estudantes inseridos nestes grupos de pesquisa acabariam sendo alguns dos que iriam estudar no Museu Nacional, como Federico Neiburg, Claudia Guebel, Carlos Kuz, Gabriela Scotto, Fernando Balbi, Axel Lazzari e, posteriormente, Virginia Vecchioli.

Além de tudo isso, houve um momento de destaque naquele Congresso, numa cerimônia que ainda hoje é muito bem lembrada pelos pesquisadores brasileiros. Mais ainda, é a primeira coisa que vem à memória dessa geração de pesquisadores do PPGAS-MN quando se propõe uma conversa sobre o convênio com a UBA. No encerramento do Congresso, lotado de participantes argentinos e estrangeiros, foi feita uma homenagem pública aos professores 
e estudantes argentinos que haviam sido perseguidos e assassinados pela ditadura militar. Nessa cerimônia, cercada de solenidade, pronunciou-se o nome de cada colega e de cada estudante desaparecido pelo terrorismo de Estado, enquanto a audiência se emocionava.

Os professores do PPGAS-MN, que conheciam de perto a violência estatal, lembram a intensa emoção que sentiram durante o desenrolar da cerimônia. Esse exercício de memória era ainda impraticável naquele tempo no Brasil. Os jovens antropólogos argentinos não se esquecem de ter chorado junto com aqueles que seriam seus futuros professores no Brasil poucos anos mais tarde.

Após aquele Congresso, ambas as partes decidiram procurar os caminhos para que os estudantes formados na Argentina pudessem circular pelas aulas do PPGAS-MN. As lágrimas tinham estreitado ainda mais os laços.

\section{Um instrumento internacionalizador: o convênio PPGAS-MN/ UFRJ-UBA}

Poucos meses depois daquele Congresso, encarregados das duas instituições foram compondo e revisando os termos de um Acordo de Cooperação que, finalmente, foi encaminhado no dia 7 de dezembro de 1987 por José Sérgio Leite Lopes, então coordenador do PPGAS-MN, ao decano da Faculdade de Filosofia y Letras da UBA, Norberto Rodríguez Bustamante.

Em 29 de dezembro de 1987 a Comissão de Pesquisa e Pós-graduação da UBA aprovou o Acordo de Cooperação ${ }^{16}$ que buscava intensificar as trocas científicas entre as duas instituições, como estabeleciam seus primeiros artigos:

Artigo $1^{\circ}$ : O presente programa tende à elaboração e eventual assinatura de um convênio destinado a facilitar e intensificar a colaboração científica entre as partes no campo da Antropologia, em particular nos temas da Antropologia, da História e ciências afins.

Artigo $2^{\circ}$ : A cooperação se aplicará em particular à elaboração, e execução e difusão de pesquisas comuns, ou à articulação de projetos de intercâmbio docente entre ambas as instituições; e consistirá em:

- Intercâmbio de missões de professores e pesquisadores em apoio aos programas docentes, e para as assessorias de pesquisas.

- Intercâmbio de informação e documentação.

- Consultas para a identificação de temas de interesse comum.

- Empreendimento de projetos conjuntos de pesquisa. 
- Organização de reuniões, seminários e outras atividades acadêmicas (Documentação do Arquivo PPGAS-MN).

O que estava por trás do Acordo era a concretização do processo de seleção dos candidatos argentinos no seu próprio país, mediante a realização das provas pertinentes. Porém, isso não era mencionado explicitamente, mas estava subentendido como parte dos intercâmbios que o Acordo provocava e permitia. ${ }^{17}$

A partir de diversos documentos constantes dos arquivos do PPGAS-MN foi possível realizar uma reconstrução dos processos institucionais compreendidos na construção da prova que se realizaria na UBA, mas que permitia a inscrição de estudantes de outras universidades.

Existiam duas partes envolvidas: o PPGAS-MN e a Seção de Antropologia Social do Departamento de Ciências Antropológicas da UBA.

O processo seletivo constava de:

(i) uma prova escrita com a duração de quatro horas, que compreendia três questões a eleger entre oito formuladas pela banca examinadora do PPGAS-MN a partir da bibliografia especialmente escolhida e informada aos candidatos (a prova era a mesma que a aplicada no Rio e igualmente anônima, mesmo se respondida em espanhol);

(ii) prova de língua estrangeira, com duração de duas horas e meia, que consistia na tradução para o espanhol ou português de um texto de antropologia em língua inglesa sendo permitido o uso do dicionário. ${ }^{18}$

Uma entrevista prova-oral fazia parte do processo de seleção a que eram submetidos os candidatos no Brasil. Os argentinos não eram submetidos a essa prova, que era substituída por uma carta na qual deviam expor as razões da candidatura, com indicação da disponibilidade de tempo para se consagrar ao curso e dos recursos disponíveis para a manutenção, assim como um relato circunstanciado da sua trajetória intelectual e seu projeto profissional.

Podiam se apresentar estudantes que estivessem terminando seu curso de graduação até dezembro do mesmo ano da prova, que era aplicada entre junho e agosto. Contudo, esses candidatos deveriam assinar um documento tomando ciência do caráter condicional de sua seleção.

No que diz respeito à dificuldade da prova, o PPGAS-MN apresentava previamente para os participantes a "Bibliografia para a prova escrita" que podia ser consultada na hora da prova.

No primeiro processo de seleção do mestrado (1988) foram selecionados capítulos de textos de Boas ("Race, language and culture"), Bourdieu 
("O desencantamento do mundo"), DaMatta ("O ofício de etnólogo, ou como ter Anthropological Blues"), Durkheim ("As regras do método sociológico" e "O suicídio"), Geertz ("A interpretação das culturas"), Gluckman ("Análise de uma situação social na zululândia moderna"), Leach ("Political systems of highland Burma"), Marx ("O Capital"), Redfield ("Peasant society and culture"), Toqueville ("O Antigo regime e a revolução") e Weber ("Economia y Sociedad").

Seguem na continuação as perguntas, escritas em espanhol, daquele processo de seleção:

\section{EXAME DE SELEÇÃO DE MESTRADO - 1988 \\ Candidatos Argentina - Buenos Aires}

Responda tres de las siguientes preguntas, usando siempre por lo menos dos de los autores citados en la bibliografía.

1. Discutir la sistematización del pensamiento religioso y sus variaciones, su relación con la estructura social y las instituciones principalmente religiosas, utilizando los textos indicados de Weber, Geertz y/o Redfield.

2. Contraponer las visiones diferenciales de la relación entre individuo y sociedad (vide Durkheim, Leach, Gluckman, Bourdieu).

3. Discutir la afirmación de Tocqueville de que la Revolución Francesa fue una revolución religiosa partiendo de los instrumentos conceptuales presentados por Weber (y/o Geertz).

4. Analizar las condiciones materiales y mentales de existencia y entrada en funcionamiento del sistema capitalista, a partir de los textos de Marx, Gluckman y Bourdieu, y considerando hechos sociológicos y/o etnográficos precisos

5. Analizar el lugar de la explicitación de las experiencias vividas por el antropólogo durante el trabajo de campo y de las condiciones sociales de estas experiencias, en la construcción de los hechos antropológicos (vide Matta, Gluckman, Boas, Leach).

6. Discutir la relación entre estrategias individuales y cambios en la estructura social, partiendo de la bibliografía indicada (vide Leach, Gluckman, Bourdieu, Marx, Weber, Durkheim).

7. Comparar las visiones de la relación entre acumulación y poder en Marx, Gluckman y Leach.

8. Contraponer el uso de la tradición como factor explicativo del comportamiento campesino en Redfield y Bourdieu. 
Nota: En todas las preguntas el candidato puede hacer uso del conjunto de la bibliografía indicada para el concurso y no sólo de los autores que figuran en esa bibliografía.

As três perguntas escolhidas precisavam ser respondidas gerando um diálogo entre os textos propostos (discutir, contrapor, comparar) e estabelecendo conexões e dependências nada simples entre autores que, em alguns casos, os estudantes argentinos tinham conhecido pouco tempo antes, na mesma preparação para a prova.

Com efeito, alguns textos não tinham sido editados na Argentina, nem podiam ser encontrados nas bibliotecas ou livrarias do país. Por isso, o PPGAS-MN enviava para a UBA cópias dos textos.

Os argentinos, em termos gerais, se saíam bem no transcurso de seu aperfeiçoamento no PPGAS-MN e eram reconhecidos pelos seus professores. Eles provinham de uma graduação específica em Antropologia e não em Ciências Sociais, como era o caso dos brasileiros. Moacir Palmeira descreve a impressão de alguns professores: "a nossa interpretação era que eles tinham uma formação de graduação melhor que a brasileira".

Este tipo de percepções, bastante presente no corpo docente do PPGAS-MN, encorajava o Programa a reforçar suas energias para seguir estimulando a circulação desses estrangeiros nas suas aulas.

A prova de ingresso facilitada pelo convênio teve vigência até 1997. Naquele ano, no marco da crise na economia brasileira, houve um corte não programado nas bolsas que foram entregues ao PPGAS-MN pelas agências científicas brasileiras. Só havia duas bolsas para os dois melhores colocados: o primeiro era um argentino. O Programa e os professores tiveram que procurar rapidamente bolsas para estudantes que já tinham ingressado e aos quais elas tinham sido prometidas. Em dois meses o problema foi resolvido. Contudo, esse evento pouco usual, junto à percepção de alguns professores do Programa de que existiam facilidades para os estudantes argentinos - como a escrita da tese em espanhol, ou a ausência de uma prova oral no ingresso - e a par de outras mudanças, como (i) o crescimento de outros programas brasileiros (especialmente os da UFRGS e da UnB) que atraíram estudantes brasileiros, e (ii) a paulatina institucionalização de espaços de encontro como a RAM, acarretou discretamente o cancelamento da prova em 1998. Apesar disso, o fluxo de argentinos pelo PPGAS-MN se manteria. 


\section{O interesse da Coordenação do PPGAS-MN na circulação de argentinos}

Nos processos de circulação internacional, como em qualquer jogo de poder científico, há interesses pessoais e institucionais postos na disputa pelo capital internacional. Pelo percurso feito até aqui, parece mais claro o possível interesse dos estudantes argentinos na passagem pelo PPGAS-MN, porém o interesse dos coordenadores desse Programa fica menos manifesto.

Pode-se supor que a circulação de argentinos pelo Programa dava uma maior relevância regional a um espaço de formação e pesquisa que já gozava de um capital internacional notável e laços estáveis com universidades e centros de pesquisa dos Estados Unidos e da França.

Esse interesse do PPGAS-MN aparece objetivado em vários gestos e negociações. Por um lado, em duas cartas idênticas escritas no dia 28 de novembro de 1988 por Afrânio Garcia Junior, então coordenador, para Mauricio Bouvin e Ana Rosato. Garcia, escrevendo em espanhol, convidava-os para o Seminario de Discusión de Investigaciones en Curso en el Área de Antropologia Rural que se realizaria nos dias 10 e 21 de abril de 1989, no Museu.

Garcia diz:

Es de especial interés para nosotros profundizar el intercambio que fuera informalmente iniciado en el II Congreso Argentino de Antropologia (agosto de 1986) y posteriormente formalizado por medio del Convenio firmado entre la Facultad de Filosofía y Letras de la UBA y el PPG em Antropologia Social de la UFRJ. Consideramos que su presencia aquí será extremadamente importante para encaminar dicho convenio no sólo con la incorporación de alumnos argentinos a los cursos de Maestrado y Doctorado del PPGAS (como está siendo realizado en los últimos meses), sino también para avanzar en la discusión de programas de docencia e investigación entre profesores e investigadores (sic).

Três questões despontam das palavras do professor Garcia.

A primeira é até que ponto aquele Congresso teria sido consagrado pelos diferentes atores envolvidos como um ato fundacional: a gênese de uma parceria que, em rigor, era mais antiga. A segunda está ligada ao interesse institucional dos coordenadores do PPGAS-MN na incorporação de mais alunos argentinos. É preciso ter em mente que, no início, cada estudante argentino ocupava uma vaga que poderia ser ocupada por mais um estudante brasileiro. A quantidade de alunos que ingressava em cada turma era de, aproximadamente, 15 estudantes. A terceira questão, que até onde foi possível pesquisar não foi concretizada nem aproveitada pela 
Seção de Antropologia Social da UBA, é que a Coordenação do PPGAS-MN desejava consolidar programas de pesquisa estáveis com professores argentinos. Isto poderia ter dado um impulso maior à Antropologia Social argentina que, pela primeira vez desde seu estabelecimento, no marco de uma universidade normalizada e com uma institucionalidade sem os riscos de períodos anteriores, via a possibilidade de planejar um programa de pesquisas de longo prazo.

O interesse dessa Coordenação na mobilidade de argentinos observa-se também na disputa com os órgãos competentes pela ampliação do número de bolsas oferecidas para esses estudantes. Os candidatos argentinos podiam se beneficiar com bolsas como as oferecidas pelo Programa de Estudantes-Convênio de Pós-Graduação (PEC-PG), providenciadas pela Capes junto ao Ministério das Relações Exteriores. À diferença das bolsas Capes tradicionais, as bolsas PEC-PG disponibilizavam o financiamento de passagens.

Numa carta ao chefe do Setor Cultural da Embaixada do Brasil na Argentina, o coordenador do PPGAS-MN, Afrânio Garcia, expressava:

Nosso empenho se deve ao fato de haver uma procura cada vez maior por parte de alunos estrangeiros de virem cursar a pós-graduação em antropologia social no MN. No caso da Argentina já está em andamento um sistema de exames in loco, aplicados na UBA. Cumpre, porém, que se institucionalize um mecanismo para as bolsas de manutenção, já que os órgãos nacionais, tais como Capes e CNPq, atendem apenas em parte às demandas internas. Se pudermos contar com o Itamaraty para a suplementação de bolsas de uma forma regular, teremos feito um avanço significativo para a consolidação de acordos internacionais de maior alcance e relevância para o desenvolvimento da Antropologia Social no país (Carta de 29 de maio de 1989).

Os estudantes internacionais comumente eram quase todos argentinos. Este tipo de mediação para facilitar a circulação dos estrangeiros se repetiu em outras ocasiões. Em 1995, numa carta à encarregada da Divisão de Cooperação e Intercâmbio da Capes, o coordenador Antonio Carlos de Souza Lima expressava a preocupação do PPGAS-MN com as dificuldades e as travas que tinham experimentado alguns estudantes latino-americanos, principalmente argentinos, quanto à possibilidade de aceder às bolsas PEC-PG.

Em recente viagem a Buenos Aires, pude verificar os diversos problemas encontrados por estudantes argentinos no uso do sistema PEC-PG via Embaixada, em que pesem os elogios feitos à atual gestão da mesma. [...] Outrossim, esperamos que, sendo quatro os alunos argentinos solicitantes, não se coloquem quaisquer 
problemas à concessão das bolsas: vigente sendo o critério de mérito e a ênfase no suporte aos países do Mercosul, espero que nosso investimento prévio e desempenho na área de Antropologia sejam reconhecidos. Os candidatos argentinos tiveram excelente desempenho em nossa testagem.

Tratava-se da operacionalização da estratégia de internacionalização da Coordenação do PPGAS-MN, neste caso, dupla. Por um lado, acrescentava seu perfil internacionalizador e sua pressão institucional em face dos órgãos estatais com financiamento. E por outro, possibilitava o acesso a uma maior quantidade de bolsas PEC-PG, só disponibilizadas para estrangeiros, o que lhe permitia oferecer um maior número de bolsas Capes e CNPq para seus candidatos brasileiros. Para conseguir manter esses fluxos, usava como recurso político o prestígio científico que alcançara no campo acadêmico, assim como a visibilidade social que a Antropologia, como linguagem de poder, já tinha no Brasil.

\section{O encontro cultural com um espaço acadêmico altamente internacionalizado}

Os processos de circulação internacional implicam o encontro de agentes portadores de culturas e habitus de internacionalização diferentes (Xavier de Brito 2004). Esse encontro pode trazer mais ou menos dificuldades de adaptação, ligadas aos costumes de cada espaço nacional e às lógicas internas de cada campo científico ou disciplinar. Pois bem, quais foram as dificuldades que os antropólogos argentinos acharam nos primeiros passos da sua circulação pelo PPGAS-MN?

Como foi indicado, o complexo panorama que apresentava a Antropologia argentina no decênio de 1980 evidenciava a falta de capacidades institucionais e de um número de profissionais altamente especializados que permitisse a criação e a consolidação de PPGs de qualidade.

Nesse contexto em que se apresentava a disciplina, não era estranho que alguns estudantes argentinos que prestavam a prova na UBA para ingressar no MN (veja-se a lista de estudantes no Anexo I) ignorassem o teor que tinham os estudos de Pós-graduação. Então, o que era aquilo que os incitava a circular pelo Brasil?

Um dos elementos que podem ajudar a compreender as motivações que levavam os argentinos a circular pelo Brasil está ligado às dificuldades profissionais que eles tinham para permanecer trabalhando na Argentina enquanto antropólogos (notadamente, a ausência de doutorados insti- 
tucionalizados e de bolsas, a par com a crise econômica argentina e seu impacto direto na universidade).

O objetivo desta seção é descrever, por meio das entrevistas realizadas com pesquisadores-antropólogos argentinos que circularam pelo PPGAS-MN, algumas das percepções que tiveram nos seus primeiros encontros com o PPGAS-MN, tentando considerar as diferenças culturais por eles percebidas. ${ }^{19}$

As entrevistas feitas no Rio de Janeiro foram realizadas no Museu Nacional, ao tempo em que as entrevistas feitas em Buenos Aires e Córdoba foram feitas em cafés ou nos apartamentos dos pesquisadores. Indagou-se sobre o começo da história profissional na disciplina, as motivações que estavam por trás da decisão de partir para o Brasil e a experiência naquele país. Deu-se espaço para que os entrevistados descrevessem a sua passagem pelo PPGAS-MN, a sua percepção pessoal e distanciada dessas vivências, e os efeitos posteriores profissionais que tal mobilidade havia produzido, segundo eles, no seu percurso como antropólogos sociais.

Algumas das entrevistas mostram que o ingresso numa pós-graduação no Brasil era uma possibilidade vantajosa para os estudantes e que, por meio da prova, ela se tornava acessível. O incipiente nível de profissionalização da Antropologia na Argentina e o escassíssimo mercado de trabalho universitário que esta disciplina apresentava - com um sistema científico naqueles anos quase inexistente - não ofereciam boas expectativas de futuro para os jovens argentinos recém-formados.

Um estudante das primeiras turmas que ingressaram por meio do acordo lembra:

Em abril daquele ano [antes de prestar a prova] fui a um Congresso em Florianópolis da Associação Brasileira de Antropologia (ABA) [refere-se à Reunião XVII de 1990]. Foi um flash, um flash. Falei para mim mesmo: "O que é isto? Isso aqui é a Antropologia?". O ambiente, a gente, o lugar. E o nível. Voltei e comecei a enviar cartas aos PPGAS no Brasil: Brasília, Campinas, São Paulo, Porto Alegre e Rio de Janeiro. Se era Sergipe, eu ia. Rio me responde: "temos um convênio com a UBA". Bom, estudemos. [Quando consegui ingressar no PPGAS-MN] eu falei para minha mãe: "vou fazer um curso, regresso em um ano e meio". Eu não dimensionava o que significava um curso de pós-graduação. Nessa época [1989], na Argentina, o fim de um curso universitário era o bacharelado, com o bacharelado você podia ser Gardel. Não tinha ninguém pós-graduado.

Três questões são relevantes neste relato. A primeira, muito recorrente nas expressões dos argentinos, é o deslumbramento que produzia esse novo mercado profissional, articulado, com o volume de produção, recursos e dis- 
cussões de qualidade. A segunda, a falta de um sistema de pós-graduação fazia com que o bacharelado tivesse um caráter profissionalizante na Argentina, enquanto no Brasil era a passagem pela pós-graduação que dava esse caráter. A terceira, a ansiedade que existia para sair da Argentina, como fruto das baixíssimas expectativas profissionais que dava o panorama da Antropologia. Em relação a este último ponto, um pesquisador que estudou no início dos anos 90 no PPGAS-MN descreve:

Eu não tinha ideia nem o que era Rio, nem o que era o $\mathrm{MN}$ : eu não sabia que tinha esse prestígio. Nada. O que me impulsionava a sair era o desastre do sistema acadêmico e científico argentino. Você sabia que se formava e não havia nada, não havia bolsas. "Você é antropólogo? Conduza um taxi". Anos de hiperinflação na Argentina. Não havia nada, não existiam cursos de Antropologia novos. Nada.

Até 2003, as bolsas que o Conselho Nacional de Pesquisas Científicas e Técnicas (Conicet), principal organismo dedicado à promoção da ciência na Argentina, outorgava eram muito poucas e com valores que não garantiam a sobrevivência de seus beneficiários. ${ }^{20}$ No Conicet, a solicitação de acesso às bolsas doutorais somente pode ser feita pelos estudantes que são menores de 30 anos de idade. Diferente do Brasil, onde não há esta restrição. Um pesquisador argentino reproduz o que, segundo ele, era a motivação dos argentinos:

Os estudantes pensam: "não consegui bolsa do Conicet, não consigo prestar concurso na Universidade; no Brasil não têm em conta a minha idade: vou tentar ingressar. Terei uma bolsa que vai me permitir viver". Então a circulação pelo Brasil é uma possibilidade dentro de uma trajetória.

Nesse contexto, o Brasil era uma alternativa formidável. Tendo em conta isso, qual era o impacto cultural que as primeiras aulas no PPGAS-MN tinham nos estudantes argentinos?

Tratava-se de uma dinâmica de estudo muito diferente daquela que tinham vivido na Argentina: seminários com poucos alunos (às vezes dois ou três), baseados muitas vezes na análise de um só texto, lido ao longo do curso na sua língua estrangeira original; e professores comprometidos politicamente na sua vida pessoal, mas que não politizavam nas suas aulas, nem realizavam uma leitura politizada dos autores.

A essas características deve-se adicionar uma outra que interessa a este estudo: a notável internacionalização e circulação do corpo de professores do PPGAS-MN, quase todos eles formados ou doutorados ou pós-doutorados fora do Brasil, além da quantidade de professores estrangeiros que colaboravam com o Programa (Cardoso de Oliveira 1992). 
Alguns exemplos: Otávio Guilherme Alves Velho defendeu sua tese de doutorado na Manchester University (Grã-Bretanha); Moacir Gracindo Soares Palmeira na Université René Descartes (Paris); Yonne Leite na University of Texas. Outros exemplos da circulação dos professores do PPGAS-MN: Gilberto Velho especializou-se em Antropologia Urbana e das Sociedades Complexas na University of Texas; Afrânio Garcia Junior, além de ter um Diploma de Estudos Econômicos Gerais (DEUG) da Université de Paris X, Nanterre, fez pós-doutorado na École des Hautes Études en Sciences Sociales (EHESS) sob a direção de Pierre Bourdieu. Também José Sérgio Leite Lopes e Luiz Fernando Dias Duarte fizeram o pós-doutorado naquela instituição, assim como Eduardo Viveiros de Castro fez seu pós-doutorado na Université de Paris X.

Ao mesmo tempo, estes e muitos outros professores do PPGAS-MN, como Lygia Sigaud e João Pacheco de Oliveira, circulavam dando cursos no exterior, especialmente na França e notadamente na EHESS, o que era influenciado pela existência de um convênio Capes/Cofecub que financiou o intercâmbio regular de docentes entre a EHESS e o PPGAS-MN.

Os indicadores oferecidos por Fry (2004) evidenciam esse nível de internacionalização. Entre os anos 1996 e 2001, os pesquisadores do PPGAS-MN realizaram 211 viagens ao estrangeiro, e foram responsáveis por $46,9 \%$ das visitas à França realizadas por pesquisadores de PPGAS. Naquele mesmo período, o PPGAS-MN foi o Programa de Antropologia Social que recebeu maior quantidade de professores visitantes estrangeiros, com 46 presenças; o seguinte, o Programa da Universidade Federal de Santa Catarina, teve 29 visitantes estrangeiros. Entre esses anos, o Programa com maior quantidade de publicações fora do Brasil foi o PPGAS-MN, com 60 publicações, seguido pelo programa da Universidade Federal de Rio Grande do Sul, com 40 publicações no exterior. Ainda nesse período, o PPGAS com maior quantidade de estudantes de mestrado e doutorado estrangeiros era o PPGAS-MN, com 18 e 22, respectivamente (dos quais 12 de mestrado e 15 de doutorado eram argentinos), seguido pelo Programa da Universidade de Brasília com 13 estudantes de mestrado e nove de doutorado (Fry 2004).

A projeção internacional e a circulação dos professores do MN aproximavam os estudantes de leituras ainda desconhecidas na Argentina. A respeito, Hugo Ratier comenta: "Eu vinha de ler muito Bourdieu no PPGAS-MN e, em Buenos Aires, ninguém conhecia Bourdieu" (Entrevista com Hugo Ratier). ${ }^{21}$

A primeira conexão com autores desconhecidos, a obrigação de ter que fazer uma leitura deles na língua original e o acesso a professores que conheciam pessoalmente e tinham um certo vínculo com esses autores, como, 
por exemplo, o caso de Afrânio Garcia com Pierre Bourdieu, colocava esses estudantes argentinos em um cenário teórico e metodológico da Antropologia Social que era bastante diferente daquele que tinham conhecido. Fazendo referência a esta primeira percepção da internacionalização da Antropologia no PPGAS-MN, Federico Neiburg destaca:

Foi essencial, foi maravilhoso. Aqui eu abri a minha cabeça. Aqui aprendi primeiro a compreender um autor e depois a criticá-lo. A Argentina, no mestrado [Flacso], nunca me exigiu ler em inglês. Aqui eu tinha que fazer a prova e, em seguida, eu tive que me esforçar para ler. Comecei a perceber as vantagens do cosmopolitismo intelectual periférico. Howard Becker veio aqui. Tive aulas com Sayad. Nas suas línguas, uma coisa maluca! (Entrevista com Federico Neiburg).

O primeiro impacto internacional aparece ligado ao modo de encarar respeitosamente os autores, que eram analisados tendo em conta o próprio contexto de produção da obra. O segundo mostra o difícil encontro com uma leitura sistemática de autores em suas línguas originais (francês e inglês), o que ao mesmo tempo indicava o rigor e o nível de profissionalização. ${ }^{22}$ Esta percepção se repete ao longo das entrevistas. Um pesquisador argentino relembra:

Chego ao Brasil e as primeiras aulas: uns sopapos! Não falava nada de português. Eles aceitavam que fizéssemos tudo em espanhol, o que no longo prazo foi pior. Eu escrevi minha tese em espanhol. Chegamos com os esquemas de conhecimento argentinos, marco teórico. Aula com Moacir e Afrânio: preparar uma aula sobre Redfield, sociedade do campesinato. "Redfield é um culturalista norte-americano que...". Eles deixaram que eu falasse e depois me disseram: "aqui não se pensa assim". Sangue, suor e lágrimas.

Com a circulação de textos e teorias nas línguas nativas dos autores não eram só palavras as que circulavam, mas também categorias, teorias e metodologias que nutriam uma discussão que se apresentava semanticamente complexa e renovada (cf. Abélès 2012). ${ }^{23}$

A partir do ingresso no Programa, a percepção sobre a disciplina expandia-se quase imediatamente para esses estudantes que, em termos gerais, só haviam lido em espanhol durante sua graduação. Alguns deles se sentiram obrigados a começar cursos de idiomas, por exemplo, na Aliança Francesa, em paralelo ao mestrado ou doutorado.

O professor Neiburg comenta: "Lembro que um dos primeiros cursos foi com Afrânio Garcia. Lemos 'La Noblesse d'État', de Pierre Bourdieu, que acabava de sair, um livro em francês! Éramos três alunos: não havia modo de não lê-lo" (Entrevista com Federico Neiburg). 
Havia que responder às perguntas mantendo uma conversação fundamentada no corpo a corpo com professores experientes. O choque da exigência simbólica daquele ambiente internacionalizado era um elemento importante da experiência vivenciada por esses estudantes. Um entrevistado comenta: "Que transformação violenta! Tínhamos que ler em média trezentas páginas por semana".

A esta caracterização pode-se adicionar o destaque que os estudantes argentinos davam ao valor dos capitais culturais e econômicos que tinham seus companheiros de curso brasileiro, que eles percebiam sendo, em sua maior parte, herdeiros de famílias bem posicionadas e já internacionalizadas. Isto também gerava um certo contraste com os colegas, definindo seu modo de chegada.

Assim, o contato com esse ambiente internacionalizado acabaria mudando percepções e trajetórias. O capital internacional acabava sendo incorporado, não sem esforços, pelos estudantes, originando a entrada no universo global mais amplo dos seus professores. Implicava para eles o ingresso na rede de contatos e fluxos internacionais que esses pesquisadores já consagrados tinham, especialmente na França.

Um pesquisador, que circulou pela França durante seu doutorado, descreve a comoção que vivenciou com a aproximação desse universo que vislumbrava pela primeira vez, tão próximo, à sua frente:

Fui para a França com uma bolsa sanduíche. Voltei da França, eu tinha visto Deus. Voltei maravilhado por aquela luz e escrevi a minha tese doutoral em quatro meses. Era a metáfora da cenoura, essa cenoura era cada vez maior, era um narcótico: que bom é isto, quantas oportunidades há. Sim, quero.

Esse depoimento descreve o "Efeito Mateo" (Merton 1968) em todo o seu esplendor: participar do PPGAS-MN gerava contatos e possibilidades profissionais diversas (acesso a bolsas, redes, jornais científicos etc.), que poucos anos antes eram impensados.

Esse leque de opções que os argentinos percebiam que se abria estava ligado à altíssima profissionalização do PPGAS-MN, à sua produção de qualidade, e ao seu constante diálogo com os principais centros de pesquisa de Antropologia Social dos países centrais.

O PPGAS-MN era, ao mesmo tempo, um espaço de recepção de referentes internacionais e uma plataforma de decolagem para o estrangeiro. 


\section{Considerações finais}

As condições de possibilidade para a construção de processos de internacionalização de longo prazo no campo científico dependem em boa medida da capacidade de um determinado espaço social: (i) para manter sua própria estabilidade e autonomia institucional em face das mudanças políticas e dos embates de outros discursos não científicos (Bourdieu 2000); (ii) para compor um sistema de pós-graduação com continuidade tanto na sua planificação de longo prazo quanto nas fontes de financiamento (Martins 2005); (iii) para estabelecer vínculos firmes, duradouros e institucionalizados com o exterior (Fry 2004).

Em relação a essas condições, o espaço da Antropologia na Argentina esteve constantemente invalidado pelas ditaduras militares durante as décadas de 1960 e 1970. Esse vai e vem não deixou acumular sentidos, nem progredir em projetos de pesquisa de longo prazo. Não existiram PPGs modernos e institucionalizados até 1990, nem financiamento para as atividades de pesquisa. Mantinha-se um diálogo interno exíguo e intensamente ideologizado, no qual era muito difícil construir lógicas de institucionalização disciplinar de longo prazo (recursos humanos qualificados, volume de produção, bolsas, teses defendidas, jornais científicos etc.). Isto se deu recentemente, nos anos 2000.

No Brasil, existiu continuidade de pesquisas (iniciadas com o projeto "Harvard-Brasil Central"); estabilidade institucional dos PPG; conexões internacionais perduráveis com os espaços centrais da disciplina; ininterrupção das reuniões de uma Associação científica forte e muito estruturada, como ABA, desde a década de 1950 até hoje (Corrêa 2003); e persistência no nível de financiamento das agências estatais que outorgavam bolsas.

A existência dessas dinâmicas sociais e condições científicas estruturais facilitaram, na visão dos antropólogos argentinos, o posicionamento da Antropologia brasileira como um espaço de prestígio e circulação internacional qualificada.

Desde os anos 70, o PPGAS-MN oferecia aos estudantes argentinos capitais pessoais e institucionais que eram atraentes e profissionalizantes: a possibilidade de uma dedicação integral aos estudos, nexos internacionais com instituições prestigiosas; incentivos para viagens; um espaço de produção de qualidade com perspectivas teórico-metodológicas inovadoras e compartilhadas com os países centrais etc.

O convênio PPGAS-MN/UBA e o dispositivo de internacionalização que foi criado (a prova de admissão administrada em Buenos Aires) transformaram-se numa janela institucional que procurou o aproveitamento 
desses capitais para os estudantes argentinos, ao mesmo tempo em que os professores do PPGAS-MN se beneficiavam com a participação dos argentinos que, tendo uma graduação específica na disciplina, segundo eles, potencializavam e fortaleciam o posicionamento deste Programa. Tratou-se de uma operação estratégica de internacionalização para ambas as instituições (Dezalay \& Garth 2002).

A partir de sua experiência pessoal, Beatriz Heredia (2009:165-166) analisa os processos históricos dessas trocas:

Um fruto dessa preocupação latino-americana de Roberto [Cardoso de Oliveira] foi a incorporação de professores e alunos de outros países da América Latina ao programa de PPGAS-MN, já desde o momento de sua criação - preocupação esta reeditada nos PPGs de Brasília e Campinas que ele também criou. Essa semente foi assim se expandindo, incluindo outras universidades que incorporam, ainda hoje, estudantes e professores argentinos; muitos dos atuais antropólogos argentinos atuantes na Argentina passaram por programas de pós-graduação brasileiros, tornando a fronteira entre os dois países, em termos de antropologia, cada vez mais fluida.

Heredia desenha uma ponte entre as duas pontas da história das dinâmicas de circulação de estudantes argentinos de Antropologia pelo Brasil. A circulação internacional, que começou nos anos 70, se institucionalizou e gerou um fluxo estável, e conexões pessoais que ainda permanecem.

O fluxo promovido pelo convênio PPGAS-MN/UBA influenciou muito as trajetórias dos pesquisadores argentinos e, mais ainda, parece ter operado, de alguma maneira, junto com outras dinâmicas institucionais, como as reuniões da ABA, a criação da RAM, e a circulação por outros PPGs brasileiros, como reorganizador cultural (Hannerz 1997) do espaço da Antropologia Social na Argentina.

Com efeito, a passagem pelo PPGAS-MN é, ainda hoje, um certo carimbo profissional e opera como um diferencial no mercado profissional argentino da antropologia. Aqueles que passaram por aquela escola intensa de profissionalização se reconhecem entre si.

Uma boa parte deles acabou sendo protagonista da institucionalização e da profissionalização dos PPGs criados nos anos 2000 na Argentina, num momento de aumento do financiamento científico do Conicet a partir de 2004. Talvez os casos mais paradigmáticos da influência do PPGAS-MN sejam, por um lado, o PPG em Antropologia Social da Faculdade de Filosofia e Humanidades da Universidade Nacional de Córdoba, onde Beatriz Heredia tinha se graduado, que contou com a participação ativa de Gustavo Sorá na criação e no processo de institucionalização, comandado a partir do Museu 
de Antropologia dependente dessa Faculdade. ${ }^{24}$ Posteriormente, a esse PPG se incorporaram outros professores doutorados no Museu, como Gustavo Blázquez, com um papel importante nessa instituição, e María Gabriela Lugones e Julieta Quirós. E, pelo outro, o PPG criado em 2001 mediante um acordo interinstitucional do Instituto de Desarrollo Económico y Social (IDES) com o Instituto de Altos Estudios Sociales (IDAES) da Universidad Nacional de San Martín (UNSAM). Neste PPG foram relevantes, entre outros, Pablo Semán, ${ }^{25}$ Axel Lazzari, ${ }^{26}$ Laura Masson, Rolando Silla, Virginia Vecchioli (agora no Brasil) e Nicolás Viotti (ver Anexo I). Nestes dois PPGs, alguns professores do PPGAS-MN foram convidados para ministrar aulas, como Otavio Velho, ${ }^{27}$ Luiz Fernando Dias Duarte, João Pacheco de Oliveira e Federico Neiburg. ${ }^{28}$

Outros argentinos, depois de circularem pelo PPGAS-MN, se inseriram em posições institucionais na Universidad de Buenos Aires, como Claudia Guebel, Fernando Balbi e Roxana Boixados; ou em outras instituições argentinas, como Carlos Kuz, Sergio Chamorro, Evangelina Mazur, María Laura Colabella, Fernanda Figurelli e Laura Navallo. Para a reinserção de muitos destes pesquisadores foi central o papel do Conicet como instituição recrutadora de recursos humanos qualificados.

Outros antropólogos optaram por ser professores no Brasil, como Federico Neiburg, Gabriela Scotto, Octavio Bonet, Hernán Gómez, Fernando Rabossi, Mariana Paladino, Horacio Sívori, Salvador Schavelzon, Román Goldenzweig e Hernán Gómez. Por sua vez, Adriana Villalón, depois de uma circulação pela Espanha, está fazendo seu pós-doutorado no IFCH Unicamp. E outros ocupam hoje posições em universidades estrangeiras, como José Pantaleón, Eloisa Martin ou Andrea Roca.

Além disso, também estudantes de mestrado e doutorado de outras instituições, assim como pesquisadores, realizaram estâncias no PPGAS-MN, como é o caso de Francisco Pazzarelli e de Guillermo Wilde no marco de seus pós-doutorados, o primeiro com Eduardo Viveiros de Castro, e o segundo com Eduardo Viveiros de Castro e Carlos Fausto. Enfim, os impactos foram múltiplos.

A descrição dos efeitos da circulação de estudantes argentinos pelo PPGAS-MN e pelo Brasil em geral na constituição e na consolidação de PPGAS na Argentina faz parte deste programa de pesquisa sobre a circulação de estudantes latino-americanos de doutorado pelo Brasil e continuará sendo indagada.

Seria proveitoso que este estudo estimulasse a descrição e a análise da conformação e da consolidação de outros fluxos estáveis no nível regional, o que implica considerar, entre outras questões, os contextos históricos, 
políticos e econômicos tanto do país de origem como do país de destino, no âmbito dos quais se deram essas dinâmicas de internacionalização; os atores (pessoas e instituições) envolvidos nesses processos; os dispositivos institucionais criados (acordos, exames etc.); e as políticas de financiamento que consolidaram essas dinâmicas. É sumamente importante, além de estratégico em termos de política científica regional, continuar analisando os modos pelos quais se produziram e estão se produzindo atualmente os fluxos sul-sul de circulação internacional.

Em relação ao caso estudado aqui, uma questão parece incontestável: a influência produzida por meio da circulação de dezenas de antropólogos argentinos pelo PPGAS-MN e pelo Brasil faz parte de uma das páginas mais relevantes da história moderna da Antropologia Social argentina.

Recebido em 22 de maio de 2018

Aprovado em 20 de agosto de 2018

Nicolás José Isola é bacharel e licenciado em Filosofia, com doutorado em Ciências Sociais pela Facultad Latinoamericana de Ciencias Sociales - Flacso. Atualmente é bolsista pós-doutoral da Fundação de Amparo à Pesquisa do Estado de São Paulo (Fapesp) pela Faculdade de Educação - Unicamp. Possui experiência na área de Sociologia, com ênfase em Sociologia da Educação, focalizando os seguintes temas: internacionalização científica e mobilidade acadêmica; institucionalização e profissionalização do campo acadêmico. É coautor do livro Investigación y Política Educativa en la Argentina post-2000 (Aique). E-mail: nicolasjoseisola@gmail.com 


\section{Anexo 1}

\section{Estudantes argentinos que circularam pelo PPGAS-MN entre os anos} 1988 e 2016

\begin{tabular}{|c|c|c|c|c|c|}
\hline $\begin{array}{c}\text { Ano } \\
\text { ingresso } \\
\text { PPGAS- } \\
\text { MN }\end{array}$ & $\begin{array}{c}\text { Fez a } \\
\text { prova } \\
\text { na } \\
\text { UBA }\end{array}$ & Nome & $\begin{array}{l}\text { Ingressou } \\
\text { no: }\end{array}$ & Orientador & Inserção institucional atual \\
\hline 1988 & Não & $\begin{array}{l}\text { Federico } \\
\text { Neiburg }\end{array}$ & Doutorado & José Sérgio Leite Lopes & Prof. PPGAS-MN/UFRJ \\
\hline \multirow{2}{*}{$\begin{array}{l}1989 \\
\text { (Primeiro } \\
\text { ano da } \\
\text { prova) }\end{array}$} & Sim & $\begin{array}{l}\text { Claudia } \\
\text { Fabiana } \\
\text { Guebel }\end{array}$ & Mestrado & Moacir Palmeira & Profa. Adjunta UBA \\
\hline & Sim & $\begin{array}{c}\text { Carlos } \\
\text { Eugenio } \\
\text { Kuz }\end{array}$ & Mestrado & Moacir Palmeira & $\begin{array}{c}\text { Prof. Adjunto Univ. Nac. de La } \\
\text { Pampa / Chefe de Trabalhos } \\
\text { Práticos UBA }\end{array}$ \\
\hline 1990 & - & - & - & - & - \\
\hline \multirow{5}{*}{1991} & Sim & Axel Lazzari & Mestrado & João Pacheco de Oliveira & $\begin{array}{c}\text { Prof. IDAES- } \\
\text { UNSAM/CONICET }\end{array}$ \\
\hline & Não & $\begin{array}{l}\text { Román } \\
\text { Goldenzwei } \\
\text { g }\end{array}$ & $\begin{array}{c}\text { Mestrado e } \\
\text { Doutorado } \\
\text { [reingresso } \\
\text { u em } 2015 \\
\text { - em curso] }\end{array}$ & $\begin{array}{l}\text { Luiz Fernando Dias } \\
\text { Duarte }\end{array}$ & $\begin{array}{l}\text { Prof. do Depto. de Ciências } \\
\text { Humanas INFES - UFF }\end{array}$ \\
\hline & Sim & $\begin{array}{l}\text { Gustavo } \\
\text { Alejandro } \\
\text { Sorá }\end{array}$ & $\begin{array}{l}\text { Mestrado e } \\
\text { Doutorado }\end{array}$ & $\begin{array}{c}\text { Mest.: Afrânio Garcia Jr. / } \\
\text { Dout.: Afrânio Garcia Jr. e } \\
\text { Luiz de Castro Faria }\end{array}$ & $\begin{array}{l}\text { Prof. Instituto de Antropología } \\
\text { de Córdoba, UNC / CONICET }\end{array}$ \\
\hline & Sim & $\begin{array}{c}\text { Maria } \\
\text { Gabriela } \\
\text { Scotto }\end{array}$ & $\begin{array}{l}\text { Mestrado e } \\
\text { Doutorado }\end{array}$ & Moacir Palmeira & $\begin{array}{l}\text { Profa. Adjunta Universidade } \\
\text { Federal Fluminense }\end{array}$ \\
\hline & Sim & $\begin{array}{l}\text { Silvina } \\
\text { Dezorzi }\end{array}$ & $\begin{array}{l}\text { Mestrado } \\
\text { inacabado }\end{array}$ & - & - \\
\hline \multirow[t]{2}{*}{1992} & Sim & $\begin{array}{l}\text { Roxana } \\
\text { Boixados }\end{array}$ & Mestrado & Giralda Seyferth & $\begin{array}{l}\text { Prof. Titular, Fac. de Filosofía y } \\
\text { Letras - UBA; Prof. Asociada, } \\
\text { Depto. Ciencias Sociales - } \\
\text { UNQ/ CONICET. }\end{array}$ \\
\hline & Sim & Nora Arias & $\begin{array}{l}\text { Mestrado e } \\
\text { Doutorado }\end{array}$ & João Pacheco de Oliveira & Falecida em 2011 \\
\hline 1994 & Sim & $\begin{array}{l}\text { Octavio } \\
\text { Bonet }\end{array}$ & $\begin{array}{l}\text { Mestrado e } \\
\text { Doutorado }\end{array}$ & $\begin{array}{l}\text { Luiz Fernando Dias } \\
\text { Duarte }\end{array}$ & Prof. IFCS-UFRJ \\
\hline 1995 & Sim & $\begin{array}{l}\text { Adriana M. } \\
\text { Villalon }\end{array}$ & $\begin{array}{l}\text { Mestrado e } \\
\text { Doutorado }\end{array}$ & Federico Neiburg & $\begin{array}{l}\text { Pesquisadora pós-doutoral } \\
\text { IFCH - Unicamp }\end{array}$ \\
\hline 1996 & Sim & $\begin{array}{l}\text { Gustavo } \\
\text { Alejandro } \\
\text { Blázquez }\end{array}$ & $\begin{array}{l}\text { Mestrado e } \\
\text { Doutorado }\end{array}$ & $\begin{array}{c}\text { Antônio Carlos de Souza } \\
\text { Lima }\end{array}$ & $\begin{array}{c}\text { Prof. Fac. Filosofía y } \\
\text { Humanidades - Univ. Nac. de } \\
\text { Córdoba / Conicet - IDH }\end{array}$ \\
\hline \multirow{3}{*}{$\begin{array}{c}1997 \\
\text { Último } \\
\text { ano da } \\
\text { prova } \\
\text { (para } \\
\text { ingressar } \\
\text { em 1998) }\end{array}$} & Sim & $\begin{array}{l}\text { Hérnan } \\
\text { Gómez }\end{array}$ & $\begin{array}{l}\text { Mestrado e } \\
\text { Doutorado }\end{array}$ & Federico Neiburg & $\begin{array}{l}\text { Prof. Univ. Federal Rural do Rio } \\
\text { de Janeiro } \\
\end{array}$ \\
\hline & Sim & $\begin{array}{c}\text { Jorge } \\
\text { Pantaleón }\end{array}$ & $\begin{array}{l}\text { Mestrado e } \\
\text { Doutorado }\end{array}$ & Federico Neiburg & $\begin{array}{c}\text { Prof. Associado Depto. de } \\
\text { Antropología - Université de } \\
\text { Montréal } \\
\end{array}$ \\
\hline & Sim & $\begin{array}{c}\text { Laura } \\
\text { Masson }\end{array}$ & $\begin{array}{l}\text { Mestrado e } \\
\text { Doutorado }\end{array}$ & Federico Neiburg & Profa. Adjunta UNSAM \\
\hline \multirow[b]{2}{*}{1998} & Sim & $\begin{array}{l}\text { Fernando } \\
\text { Balbi }\end{array}$ & Doutorado & Moacir Palmeira & Prof. Adjunto UBA / CONICET \\
\hline & Sim & $\begin{array}{c}\text { Sergio } \\
\text { Chamorro }\end{array}$ & Mestrado & Lygia Sigaud & $\begin{array}{c}\text { Prof. Depto. de Ciencias } \\
\text { Sociales da UNQ e da Fac. CS } \\
\text { UNICEN }\end{array}$ \\
\hline 1999 & Não & $\begin{array}{l}\text { Fernando } \\
\text { Rabossi }\end{array}$ & Doutorado & Federico Neiburg & $\begin{array}{l}\text { Prof. Depto. de Antropología } \\
\text { Cultural - IFCS/UFRJ }\end{array}$ \\
\hline
\end{tabular}




\begin{tabular}{|c|c|c|c|c|c|}
\hline \multirow{3}{*}{1999} & Não & $\begin{array}{l}\text { Virginia } \\
\text { Vecchioli }\end{array}$ & $\begin{array}{c}\text { Mestrado e } \\
\text { Doutorado }\end{array}$ & Federico Neiburg & $\begin{array}{c}\text { Profa. Depto. de Ciências } \\
\text { Sociais - Univ. Federal de Santa } \\
\text { Maria }\end{array}$ \\
\hline & Não & $\begin{array}{l}\text { Mariana } \\
\text { Paladino }\end{array}$ & Doutorado & $\begin{array}{l}\text { Antonio Carlos de Souza } \\
\text { Lima }\end{array}$ & $\begin{array}{c}\text { Profa. na Fac. de Educação - } \\
\text { UFF }\end{array}$ \\
\hline & Não & $\begin{array}{l}\text { Evangelina } \\
\text { Mazur }\end{array}$ & $\begin{array}{c}\text { Mestrado e } \\
\text { Doutorado }\end{array}$ & $\begin{array}{l}\text { Luiz Fernando Dias } \\
\text { Duarte }\end{array}$ & $\begin{array}{c}\text { Profa. Mestrado en Human. y } \\
\text { Ciencias Sociales - UNQ / Fac. } \\
\text { de Trabalho Social - UNLP }\end{array}$ \\
\hline 2000 & - & - & - & - & - \\
\hline \multirow{4}{*}{2001} & Não & $\begin{array}{l}\text { Rolando } \\
\text { Silla }\end{array}$ & Doutorado & Otávio Velho & $\begin{array}{c}\text { Prof. IDAES-UNSAM / } \\
\text { CONICET }\end{array}$ \\
\hline & Não & $\begin{array}{c}\text { Eloísa } \\
\text { Martín }\end{array}$ & Doutorado & Otávio Velho & $\begin{array}{c}\text { Profa. Associada na United Arab } \\
\text { Emirates University }\end{array}$ \\
\hline & Não & $\begin{array}{l}\text { Horacio } \\
\text { Federico } \\
\text { Sívori }\end{array}$ & Doutorado & $\begin{array}{l}\text { Luiz Fernando Dias } \\
\text { Duarte }\end{array}$ & $\begin{array}{l}\text { Prof. Instituto de Medicina } \\
\text { Social - UERJ }\end{array}$ \\
\hline & Não & $\begin{array}{c}\text { Silvina } \\
\text { Bustos } \\
\text { Argañaraz }\end{array}$ & Mestrado & João Pacheco de Oliveira & Atualmente sem inserção \\
\hline 2002 & Não & $\begin{array}{c}\text { María } \\
\text { Gabriela } \\
\text { Lugones }\end{array}$ & $\begin{array}{c}\text { Mestrado e } \\
\text { Doutorado }\end{array}$ & $\begin{array}{c}\text { Antonio Carlos de Souza } \\
\text { Lima }\end{array}$ & $\begin{array}{l}\text { Profa. Fac. de Lenguas e } \\
\text { Pesquisadora no CIFFyH - } \\
\text { Univ. Nac. de Córdoba }\end{array}$ \\
\hline \multirow{2}{*}{2003} & Não & $\begin{array}{c}\text { Laura } \\
\text { Zapata } \\
\text { González }\end{array}$ & Doutorado & Giralda Seyferth & $\begin{array}{c}\text { Profa. da Univ. Nac. de José C. } \\
\text { Paz }\end{array}$ \\
\hline & Não & $\begin{array}{l}\text { Andrea } \\
\text { Lacombe }\end{array}$ & $\begin{array}{l}\text { Mestrado e } \\
\text { Doutorado }\end{array}$ & $\begin{array}{l}\text { Mest.: Otávio Velho / } \\
\text { Dout.: Adriana Vianna }\end{array}$ & $\begin{array}{c}\text { Pesquisadora Centro de } \\
\text { Investig. Jurídicas y Sociales - } \\
\text { Univ. Nac. de Córdoba }\end{array}$ \\
\hline \multirow{3}{*}{2004} & Não & $\begin{array}{l}\text { María Laura } \\
\text { Colabella }\end{array}$ & Doutorado & Lygia Sigaud & $\begin{array}{c}\text { Profa. Adj. na Univ. Nac. Arturo } \\
\text { Jauretche. Profa. convidada } \\
\text { Mestrado Sociología Cs. } \\
\text { Políticas - FLACSO }\end{array}$ \\
\hline & Não & $\begin{array}{l}\text { Julieta } \\
\text { Quirós }\end{array}$ & $\begin{array}{c}\text { Mestrado e } \\
\text { Doutorado }\end{array}$ & $\begin{array}{l}\text { Mest.: Lygia Sigaud } \\
\text { Dout:. Lygia Sigaud e } \\
\text { Federico Neiburg }\end{array}$ & $\begin{array}{c}\text { Profa. na Univ. Nac. de Córdoba } \\
\text { / CONICET }\end{array}$ \\
\hline & Não & $\begin{array}{c}\text { Andrea } \\
\text { Claudia } \\
\text { Roca }\end{array}$ & $\begin{array}{c}\text { Mestrado e } \\
\text { Doutorado }\end{array}$ & João Pacheco de Oliveira & $\begin{array}{c}\text { Profa. Dep. of French, Hispanic } \\
\text { and Italian Studies - Univ. of } \\
\text { British Columbia }\end{array}$ \\
\hline 2005 & Não & $\begin{array}{l}\text { Fernanda } \\
\text { Figurelli }\end{array}$ & $\begin{array}{l}\text { Mestrado e } \\
\text { Doutorado }\end{array}$ & Moacir Palmeira & $\begin{array}{l}\text { Pesquisadora no CONICET - } \\
\text { Univ. Nac. de Misiones }\end{array}$ \\
\hline \multirow{2}{*}{2006} & Não & $\begin{array}{c}\text { Nicolás } \\
\text { Viotti }\end{array}$ & Doutorado & $\begin{array}{l}\text { Luiz Fernando Dias } \\
\text { Duarte }\end{array}$ & $\begin{array}{c}\text { Prof. FLACSO e UNSAM / } \\
\text { CONICET }\end{array}$ \\
\hline & Não & $\begin{array}{l}\text { Salvador } \\
\text { Schavelzon }\end{array}$ & Doutorado & Marcio Goldman & Prof. Unifest - Osasco \\
\hline 2008 & Não & $\begin{array}{c}\text { Laura } \\
\text { Navallo } \\
\text { Coimbra }\end{array}$ & $\begin{array}{l}\text { Mestrado e } \\
\text { Doutorado }\end{array}$ & $\begin{array}{l}\text { Antonio Carlos de Souza } \\
\text { Lima }\end{array}$ & $\begin{array}{c}\text { Profa. Auxiliar Comunicación } \\
\text { Social, Sede Regional Tartagal - } \\
\text { UNSA }\end{array}$ \\
\hline \multirow[t]{2}{*}{2012} & Não & $\begin{array}{c}\text { María } \\
\text { Cecilia Díaz }\end{array}$ & $\begin{array}{c}\text { Mestrado e } \\
\text { Doutorado }\end{array}$ & $\begin{array}{l}\text { Luiz Fernando Dias } \\
\text { Duarte }\end{array}$ & $\begin{array}{c}\text { Profa. Fac. Filosofía y } \\
\text { Humanidades - Univ. Nac. de } \\
\text { Córdoba }\end{array}$ \\
\hline & Não & $\begin{array}{l}\text { Carolina } \\
\text { Castellitti }\end{array}$ & $\begin{array}{l}\text { Mestrado e } \\
\text { Doutorado }\end{array}$ & $\begin{array}{l}\text { Luiz Fernando Dias } \\
\text { Duarte }\end{array}$ & Atualmente sem inserção \\
\hline 2016 & Não & $\begin{array}{c}\text { Nahuel } \\
\text { Blázquez }\end{array}$ & $\begin{array}{c}\text { Mestrado e } \\
\text { Doutorado }\end{array}$ & Adriana Vianna & Doutorando \\
\hline
\end{tabular}

Nota: Informações obtidas por meio de indagações aos pesquisadores. Quando não foi possível, buscaram-se dados nos CV Lattes e sítios web institucionais. Uma nota deve ser feita: os irmãos Claudia e Fabio Mura, nascidos na Argentina, realizaram o mestrado e o doutorado no PPGAS-MN, porém, quando chegaram ao Brasil, provinham da Itália, onde viviam desde pequenos, sem terem nenhum laço nem conhecimento da circulação que tinha origem na Argentina como fruto do convênio. Por este motivo, eles ficaram fora desta lista. 


\section{Notas}

1 Agradeço o convite de Afrânio Garcia para apresentar uma versão preliminar deste trabalho no Seminário Groupe de Réflexion sur le Brésil Contemporain (GRBC), na École des Hautes Études en Sciences Sociales (EHESS) de Paris, em abril de 2018. Agradeço também os comentários realizados por Monique de Saint-Martin naquela oportunidade. Este trabalho não teria sido possível sem a ajuda e a cordialidade de Federico Neiburg, que colocou à minha disposição os arquivos do PPGAS-MN, e sem a generosidade dos entrevistados. Finalmente, agradeço à Fapesp pelo apoio financeiro (Processo 2015/11129-0) e à Ana Maria F. de Almeida pela dedicação e colaboração como supervisora. Registre-se, porém, como de praxe, que as ideias aqui expressas são de minha inteira responsabilidade.

2 Durante essa década existiram outros projetos de cooperação. Consulte-se Cardoso de Oliveira (1992); Leite Lopes (1992); Garcia (2009a; 2009b); Sigaud (2008); Leite Lopes (2013).

3 Em 1977, teve início o curso de doutorado (Leite Lopes 1992).

4 "Na ditadura militar, o Museu foi um lugar relativamente afastado dos combates na universidade e isso permitiu que o PPGAS-MN fosse uma 'região de refúgio' de antropólogos, com muito capital social e outros capitais que permitiam protegê-los. Outros espaços, como o IFCS-UFRJ, foram incendiados pelos militares" (Entrevista com Federico Neiburg).

5 Formado em Medicina, realizou estudos de pós-graduação na Universidade de Columbia e dedicou-se à Arqueologia. Foi diretor do Instituto de Antropologia da Universidad del Litoral (Rosario, Argentina).

6 Nessa linha, Peter Fry (2004:242) expressa: “É como se a antropologia brasileira - tão geopoliticamente periférica quanto à do Sri Lanka do ponto de vista do 'centro' - legitimasse a antropologia do establishment tão duramente criticada em outros lugares periféricos. A relação da antropologia brasileira com as antropologias americana, inglesa e francesa é de aliança» (os destaques no texto são do autor).

7 O professor argentino Roberto Ringuelet comenta: “Com o apoio do Dr. Alberto Rex Gonzalez, que foi meu professor em La Plata, dediquei-me à seleção de uma bolsa da área específica da Fundação Ford para fazer a pós-graduação no PPGAS-MN" (Entrevista com Roberto Ringuelet). Ele ficou no Brasil de agosto de 1970 até agosto de 1972.

8 Posteriormente, Heredia realizaria seu doutorado no PPGAS-MN (1985) e se tornaria professora associada no Instituto de Filosofia e Ciências Sociais (IFCS) da UFRJ.

9 Existiram exceções. Por exemplo, Gino Germani, diretor do Departamento de Sociologia da UBA, convidou Ralph Beals, antropólogo cultural norte-americano, 
criador e primeiro diretor do Departamento de Sociologia e Antropologia da Universidade de Califórnia em Los Angeles (UCLA), para passar um semestre na universidade, ministrando a disciplina Antropologia Social pela primeira vez na Argentina, no ano de 1962 (Guber 2014). Também naqueles anos, uma minoria de estudantes foi estudar no exterior, como Esther Hermitte, nos EUA; e posteriormente Hebe Vessuri, na Inglaterra; Leopoldo Bartolomé, nos EUA; Eduardo Archetti, na França, entre outros (cf. Guber \& Visacovsky, 2000).

10 No espaço argentino da Antropologia, e nas Ciências Sociais e Humanas em geral, o problema clássico da demarcação das fronteiras entre o nacional e o internacional tendeu a ser resolvido pelo fortalecimento da demarcação da fronteira interna, projetando uma sombra e antipatia sobre o estrangeiro e obstruindo o ingresso daquilo que era suspeito de ser colonizador da própria cultura. Possivelmente, o caso da Universidad Nacional de Misiones seja uma das exceções, dado que seu diretor, Leopoldo Bartolomé, formado na UBA e doutorado na Universidade de Wisconsin-Madison (1974), onde ingressou graças à ajuda financeira da Fundação Ford, permitiu a abertura à antropologia norte-americana (Ratier \& Guebel 2004). Esse curso de graduação foi criado em 1974 sob a inspiração de Bartolomé e Luis Gatti (Ratier 2010).

11 No Brasil, assumiu como chefe do Departamento de Sociologia e Antropologia na Universidade Federal de Paraíba.

12 Com efeito, alguns estudantes da UBA realizaram uma paródia do enterro da antropologia funcionalista com um caixão nos corredores da Faculdade de Filosofia e Letras. Estes posicionamentos críticos devem ser considerados numa perspectiva mais ampla, que excede este estudo. De fato, o desprezo pelo funcionalismo não foi uma exclusividade do caso argentino, ao contrário, deu-se em muitos outros espaços nacionais, como no México, na França e inclusive nos EUA.

13 Além de impulsionar a promoção do diálogo entre os países da região, a RAM, de certa forma, modificou algumas das configurações até então institucionalizadas no campo da Antropologia brasileira, suavizando predomínios e dando uma maior visibilidade a PPGs prestigiosos.

14 Em setembro de 1983, na agonia do processo militar, foi realizado em Posadas o Primeiro Congresso Argentino de Antropologia Social (Ratier 2010).

15 Ratier foi importante na trajetória de alguns antropólogos no Brasil. Ele mesmo relembra: "mostrei para o Federico Neiburg o trabalho de Sergio Leite Lopes nas fábricas com vila operária, e ele saiu com aquele referencial teórico para trabalhar na fábrica de Loma Negra. O contato de Federico com Sergio foi estabelecido e ele ficou ligado ao Museu e à sua pós-graduação" (Entrevista com Hugo Ratier).

16 O Conselho Diretivo da Faculdade de Filosofia e Letras da UBA aprovou-o por meio da Resolução n. 819 (10 de maio de 1988, expediente nº 861.393/87).

17 Naqueles anos, outro Acordo de Cooperação foi assinado entre o PPGAS-MN e a Escuela de Antropología de la Facultad de Humanidades y Artes de la 
Universidad Nacional de Rosario (Resolução do Conselho Diretivo da Faculdad de Humanidades y Artes de la Universidad Nacional de Rosario n. 177/91). Numa carta enviada em 3 de junho de 1991, o coordenador do PPGAS-MN à época, João Pacheco de Oliveira, escreveu para o professor Garbulsky, diretor da Escuela de Antropología de la Facultad de Humanidades y Artes de la Universidad Nacional de Rosario: "Em seu conteúdo, o Acordo repete as disposições do instrumento anterior, celebrado com a UBA, de maio de 1987, atualmente tendo sido renovado". Contudo, esse Acordo definia que os candidatos da cidade de Rosario fizessem a prova também na UBA.

18 A partir de 1991 se adicionaria, na Argentina, uma prova de conhecimento instrumental em francês.

19 Em algumas ocasiões, para mostrar a continuidade de alguns matizes, se colocaram os relatos de pesquisadores que estiveram no PPGAS-MN alguns anos antes da assinatura do convênio.

20 Alguns dados para se ter uma ideia mais completa desse panorama ligado à carreira de pesquisador na Argentina e da evolução das bolsas de estudo anuais. No Conicet, em 1997, ingressaram 125 pesquisadores e 300 bolsas foram concedidas. Em 2001, se incorporaram 160 pesquisadores e 30 bolsistas. Em 2004, uma mudança substancial ocorre: nesse ano, entraram 400 pesquisadores e 1.300 bolsas foram concedidas. Finalmente, em 2012, o Conicet incorporou 606 pesquisadores e 3.900 bolsas de doutorado e pós-doutorado foram dadas. Fonte: http://www.conicet.gov. ar/conicet-30-anos-de-democracia/

21 Para alguns, essa internacionalização excedia o âmbito do Museu. Para os argentinos, uma das mostras disto era que o consumo cultural de Rio de Janeiro ia além do português. Federico Neiburg realça suas impressões daqueles anos: "O Rio de Janeiro era totalmente cosmopolita. Nas prateleiras das livrarias daqui havia livros em inglês e em francês. Isto não acontecia no México, nem na Argentina" (Entrevista com Federico Neiburg).

22 "Lembro-me que no Museu estavam procurando desesperadamente a tradução em inglês do Capital que tinha corrigido Marx para discutir um termo de Lenin sobre a formação do campesinato. Então, aí eles iam procurar como estava escrito o conceito, esta era a preocupação. Era Afrânio Garcia quem estava procurando desesperadamente" (Entrevista com Hugo Ratier).

23 Outro pesquisador argentino destaca: "O curso do $\mathrm{MN}$ foi para mim um verdadeiro aperfeiçoamento em diversas áreas e, acima de tudo, um sistema de aprendizagem metodológica no estudo, nas formas de expressão e nos laços acadêmicos. Neste sentido, fui marcado profissionalmente".

24 Nesse processo foram importantes os papéis de Andrés Laguens e Mirta Bonnin.

25 Realizou o pós-doutorado no PPGAS-MN (2001-2003). Atualmente é pesquisador de Conicet e professor em IDAES/UNSAM. 
26 Realizou o mestrado no PPGAS-MN e o doutorado na Universidade de Columbia (EUA).

27 Membro do Comitê Assessor Externo do doutorado em Antropologia Social da Universidad Nacional de San Martín.

28 Os laços do IDAES/UNSAM com o PPGAS-MN propiciaram um acordo institucional que possibilitou a circulação de professores brasileiros pela Argentina através do Programa Bi-Nacional "Centros Asociados de Posgrado en Antropología - Brasil Argentina" (PPGAS/UFRGS, Museu Nacional/UFRJ e IDAES/UNSAM). Proyecto CAPG-BA 069/13, PIESCI/SPU - Capes. 


\section{Referências bibliográficas}

ABÉLÈS, Marc. 2012. Antropología de la globalización. Buenos Aires: Ediciones del Sol.

ALMEIDA, Ana Maria et al. (orgs.). 2004. Circulação internacional e formação intelectual das elites brasileiras. Campinas: Unicamp.

ANDERSON, Benedict. 1993. Comunidades Imaginadas. Reflexiones sobre el origen y la difusión del nacionalismo. Cidade do México: FCE.

BARTOLOMÉ, Leopoldo (coord.). 2007. Argentina: la enseñanza de la antropología social en el contexto de las ciencias antropológicas. Red de Antropologías del Mundo/World Anthropologies Network/LASA-Ford. Disponível em http://www.ram-wan. net/old/documents/06_documents/ informe-argentina.pdf. Acesso em 10/03/2017.

BAUMAN, Zygmunt. 1997. Legisladores e intérpretes. Bernal: Unqui.

BEIGEL, Fernanda \& SABEA, Hanan. 2014. Academic dependency and professionalization in the south: perspectives from the periphery. Mendoza/ Rio de Janeiro: Ediunc/Sephis.

BOURDIEU, Pierre. 2000. Los usos sociales de la Ciencia. Buenos Aires: Nueva Visión. . 2001. "Postscriptum. Del campo nacional al campo internacional". In: P. Bourdieu, Las estructuras sociales de la economía. Buenos Aires: Manantial. pp. 253-262.

. 2002. "Les conditions sociales

de la circulation internationale des idées". Actes de la recherche en sciences sociales, 5:3-8.

. 2006. "La identidad y la representación: Elementos para una reflexión crítica sobre la idea de región". Debate, n. 67, Flacso-Ecuador, abril.

CANÊDO, Letícia \& GARCIA, Afrânio.
2004-2005. "Les Boursiers brésiliens et l'accès aux formations d'excellence internationales". Cahiers du Brésil Contemporain, n. 57/58, 59/60:21-48. CARDOSO DE OLIVEIRA, Roberto. 1992. "Depoimento: rememorando um Programa". Antropologia Social. Comunicações do PPGAS, n. 2:45-56, nov. . 2006. "Antropologias periféricas versus antropologias centrais". In: R. Cardoso de Oliveira, O Trabalho do Antropólogo. São Paulo: Ed. Unesp. CORRÊA, Mariza. 1987. História da Antropologia no Brasil (1930-1960). Testemunhos. São Paulo: Vértice-Editora da Unicamp.

2003. As reuniões brasileiras de antropologia: cinquenta anos (19532003). Brasília: ABA.

COSER, Lewis. 1968. Hombres de ideas: El punto de vista de un sociólogo. Cidade do México: FCE.

DEZALAY, Yves \& GARTH, Bryant. 2002. La Mondialisation des guerres de palais. Paris: Seuil.

FRY, Peter. 2004. "Internacionalização da disciplina". In: G. Lins Ribeiro \& W. Trajano Filho, O campo da antropologia no Brasil. Rio de Janeiro/ Brasília: Editora Contracapa/ABA. pp. 227-248.

GARCIA, Afrânio. 2005. "Circulation internationale et formation d'une 'école de pensée' latino-américaine (19452000)". Social Science Information, v. 44, n. 2/3:521-555.

. 2009a. "Fundamentos empíricos da razão antropológica: a criação do PPGAS e a seleção das espécies científicas". Mana, 15 (2):411-447.

. 2009b. "Les disciplines de la 'Mission française' et la réception de l'anthropologie structural au Brésil: retour sur un mythe d'origine". Cahiers de la Recherche sur l'éducation et les 
savoirs, Hors série n. 2:57-92.

GRIMSON, Alejandro \& SEMÁN, Pablo. 2006. "La antropología brasileña contemporánea. Contribuciones para un diálogo latinoamericano". Journal of the World Anthropology Network, 2:155-165.

GUBER, Rosana. 2008. "Committed or Scientific? The Southern Whereabouts of Social Anthropology and Antropología Social in 1960-70 Argentina". In: A. Boskovic (ed.), Other People's Anthropologies. Ethnographic Practice on the Margins. Oxford: Berghahn. pp. 110-24.

GUBER, Rosana. 2010. “El compromiso profético de los antropólogos sociales argentinos, 1960-1976". Avá, (16), 1.

GUBER, Rosana. 2014. "Leopoldo: inicios y formación de un creador de instituciones. Los comienzos en los confines: la no-opción por la Antropología social de Leopoldo J. Bartolomé y Carlos A. Herrán". Avá, 25:35-62, Universidad Nacional de Misiones.

GUBER, Rosana \& VISACOVSKY, Sergio. 1998. "Controversias filiales: la imposibilidad genealógica de la antropología social de Buenos Aires". Relaciones de la Sociedad Argentina de Antropología, XXII-XXIII:25-53. 2000. "La antropología social en la Argentina de los ‘60 y ‘70. Nación, marginalidad crítica y el 'otro' interno". Desarrollo Económico, v. 40, n. 158:289-316, jul.-set.

GUEBEL, Claudia et al. 1996. "Entrevista com Roberto Cardoso de Oliveira". Publicar, v. 6:89-100, Buenos Aires.

HANNERZ, Ulf. 1997. "Fluxos, fronteiras, híbridos: palabras-chave da antropología transnacional". Mana, 3 (1).

HEILBRON, Johan; GUILHOT, Nicolas \& LAURENT, Jean Pierre. 2008. "Toward a transnational history of the social sciences". Journal of the
History of the Behavioral Sciences, 44 (2):146-160.

HEREDIA, Beatriz. 2009. "Conexões: Roberto Cardoso de Oliveira e o ensino da Antropologia na América Latina". Anuário Antropológico, v. 1:163-173. ISU - UNESCO. 2018. Education: Inbound internationally mobile students by continent of origin. Disponível em http://data.uis.unesco.org/Index. aspx. Acesso em 10/04/2017.

KARADY, Victor. 1998. "La république des lettres des temps modernes [L'internationalisation des marchés universitaires occidentaux avant la Grande Guerre]". Actes de la recherche en sciences sociales, v. 121122:92-103, mars.

LARAIA, Roque de Barros. 2010. Roque de Barros Laraia (depoimento, 2008). Rio de Janeiro: CPDOC/FGV; LAU/ IFCS/UFRJ; ISCTE/IUL.

LEITE LOPES, José Sergio. 1992. "20 anos do Programa de Pós-graduação em Antropologia Social do Museu Nacional/UFRJ". Antropologia Social. Comunicações do PPGAS, 2:1-8, nov. 2013. "Entrevista com Moacir Palmeira". Horizontes Antropológicos, 19 (39) :435-457.

LIMONGI, Fernando. 1989. “Mentores e clientelas da Universidade de São Paulo". In: Sergio Miceli (org.), História das ciências sociais no Brasil. São Paulo: Vértice/Idesp/Finep.

LOVISOLO, Hugo. 2000. Vecinos distantes. Universidad y ciencia en Argentina y Brasil. Buenos Aires: del Zorzal. MARTINS, Carlos Benedito (org). 2005. "Notas sobre a formação do sistema nacional de pós-graduação". In: C. Martins, Para onde vai a Pós-graduação em Ciências Sociais no Brasil. Bauru, SP: Edusc.

MERTON, Robert. 1968. "The Matthew effect in science". Science, 159: 56-63. 
MICELI, Sergio (org.). 1993. A Fundação Ford no Brasil. São Paulo: Sumaré/Fapesp. 1995. História das Ciências Sociais no Brasil. São Paulo: Sumaré/Fapesp. MUÑOZ, Marie-Claude \& GARCIA, Afrânio. 2004-2005. 《Les étudiants brésiliens en France: parcours intellectuel et inscription académique". Cahiers du Brésil contemporain, 57/58-59/60:107-128.

NEUFELD, María Rosa; SCAGLIA, María Cecilia \& NAME, María Julia, (comps.). 2015. "Y el museo era una fiesta ...": Documentos para una historia de la antropología en Buenos Aires. Ciudad Autónoma de Buenos Aires: Editorial de la Facultad de Filosofía y Letras Universidad de Buenos Aires.

OECD. 2001. Trends in International Migration 2001: Continuous Reporting System on Migration, Paris: OECD Publishing.

PACE, Richard. 2014. "O legado de Charles Wagley: uma introdução". Bol. Mus. Para. Emílio Goeldi. Ciênc. hum., 9 (3):597-602.

PALERMO, Vicente. 2015. La alegría y la pasión. Relatos brasileños y argentinos en perspectiva comparada. Buenos Aires: Katz.

PERAZZI, Pablo. 2014. "Peronismo, pos-peronismo y profesionalización: trayectorias académicas, estrategias de auto-preservación y círculos discipulares en la antropología porteña, 1945-1963". Sociohistórica, 34.

PIERSON, Donald. 1987. "Algumas atividades no Brasil em prol da Antropologia e outras ciências" In: M. Corrêa (org.), História da Antropologia no Brasil (1930-1960). Testemunhos. São Paulo: Vértice-Editora da Unicamp. POUSADELA, Inés. 2007. "Las políticas públicas y las matrices nacionales de cultura política". In: A. Grimson (comp.), Pasiones nacionales. Buenos Aires: Edhasa.

RATIER, Hugo. 1983. "Antropología Social en Argentina y Brasil: teorías y prácticas". Ponencia al Primer Congreso Argentino de Antropologia Social, Posadas.

. 2010. "La antropología social argentina: su desarrollo". Publicar, Argentina, Año VIII, n. IX:17-46.

RATIER, Hugo \& RINGUELET, Roberto. 1997. "La Antropología Social en la Argentina: un producto de la democracia". Horizontes Antropológicos, 3 (7):10-23.

RATIER, Hugo \& GUEBEL, Claudia. 2004. "Las antropologías argentina y brasileña según algunos testimonios: exilios, tránsitos y permanencias". Raízes, Campina Grande, 23 (0102):140-158.

SCHWARTZMAN, Simon. 1991. A Space for Science: the Development of the Scientific Community in Brazil. University Park: Pennsylvania State University Press.

SILLA, Rolando. 2012. "Raza, raciología y racismo en la obra de Marcelo Bórmida". Revista Del Museo de Antropología, 5 (1):65-76.

SIMÉANT, Johanna (dir.). 2015. Guide de l'enquête globale en sciences sociales, Paris: CNRS Editions.

THOMAZ, Omar \& CABRAL, João. 2011. "Radcliffe-Brown v. Antonio Candido: um debate inacabado". Mana, Rio de Janeiro, v. 17, n. 1:187-204.

VELHO, Gilberto. 2012. "Homenagem a Gilberto Velho". Mana, 18 (1):173-212 .

VELHO, Otávio. 2003. "A pictografia da tristesse: uma antropologia do nation-building nos trópicos". Ilha Revista de Antropologia, Florianópolis, v. 5, n. 1:05-22, jan.

VERGER, Jacques. 1991. "La mobilité étudiante au Moyen Âge". Histoire 
de l'Éducation, 50:05-90.

VESSURI, Hebe. 1973. "La observación participante en Tucumán 1972". Revista Paraguaya de Sociología, 27 (59):59-76.

WAGNER, Anne \& RÉAU, Bertrand. 2015. "Le capital international: un outil d'analyse de la reconfiguration des rapports de domination". In: J. Siméant (dir.), Guide de l'enquête globale en sciences sociales. Paris: CNRS Editions. pp. 33-46.

WILLEMS, Emílio. 1987. “Dezoito anos no Brasil. Resumo de atividades didáticas e científicas". In: Mariza Corrêa (org.), História da Antropologia no Brasil (1930-1960). Testemunhos. São Paulo: Vértice-Editora da Unicamp.

XAVIER DE BRITO, Angela. 2004. "Habitus de herdeiro, habitus escolar. Os sentidos da internacionalização nas trajetórias dos estudantes brasileiros". In A. Almeida et al. (ed.), Circulação internacional e formação intelectual das elites brasileiras. Campinas: Editora Unicamp. pp. 85-104.

\section{Entrevistas realizadas (ordem cronológica)}

- Gustavo Sorá, realizada no dia 11 de setembro de 2015, na cidade de Córdoba, Argentina.

- Federico Neiburg, realizada no dia 5 de outubro de 2016, na cidade do Rio de Janeiro, Brasil.

- Moacir Palmeira, realizada no dia 6 de outubro de 2016, na cidade do Rio de Janeiro, Brasil.

- Hugo Ratier, realizada no dia 27 de fevereiro de 2017, na cidade de Buenos Aires, Argentina.

- Claudia Guebel, realizada no dia 27 de fevereiro de 2017, na cidade de Buenos Aires, Argentina.

- Mauricio Boivin, realizada no dia 1 de março de 2017, na cidade de Buenos Aires, Argentina.

- Fernando Balbi, realizada no dia 6 de abril de 2017 (teleconferência) e no dia 14 de julho de 2017, na cidade de Buenos Aires, Argentina.

- Roberto Ringuelet, entrevista escrita, por correio eletrônico, realizada no dia 10 de abril de 2017.

- Roxana Boixados, realizada no dia 15 de junho de 2017, na cidade de Buenos Aires, Argentina.

- Laura Masson, realizada no dia 16 de junho de 2017, na cidade de Buenos Aires, Argentina.

- María Cecilia Díaz, realizada no dia 22 de junho de 2017, na cidade de Córdoba, Argentina.

- Gustavo Blazquez, realizada no dia 23 de junho de 2017, na cidade de Córdoba, Argentina. 
- María Gabriela Lugones, realizada no dia 23 de junho de 2017, na cidade de Córdoba, Argentina.

- Carlos Eugenio Kuz, realizada no dia 10 de julho de 2017, na cidade de Buenos Aires, Argentina.

- Axel Lazzari, realizada no dia 10 de julho de 2017, na cidade de Buenos Aires, Argentina.

- Rolando Silla, realizada no dia 12 de julho de 2017, na cidade de Buenos Aires, Argentina.

- Pablo Semán, realizada no dia 18 de julho de 2017, na cidade de Buenos Aires, Argentina.

- Virginia Vecchioli, entrevista escrita, por correio eletrônico, realizada no dia 3 de maio de 2018. 


\section{ARGENTINOS À BRASILEIRA. A CIRCULAÇÃO DE ANTROPÓLOGOS ARGENTINOS PELO MUSEU NACIONAL (PPGAS-MN/UFRJ)}

\section{BRAZILIAN-STYLE ARGENTINES. THE CIRCULATION OF ARGENTINE ANTHROPOLOGISTS THROUGH THE NATIONAL MUSEUM (PPGAS-MN / UFRJ)}

\begin{abstract}
Resumo
Como se produzem e consolidam os fluxos de circulação internacional na América Latina? Como tem mostrado uma ampla literatura, a circulação internacional de pessoas não se produz automaticamente, mas é produto de dinâmicas sociais complexas. Esse trabalho reconstrói os processos pelos quais pode se produzir um fluxo de estudantes argentinos em direção ao Programa de Pós-Graduação em Antropologia Social do Museu Nacional (PPGAS-MN). A partir de um trabalho de arquivo no PPGAS-MN e de entrevistas com professores e ex-estudantes, o estudo revela os mecanismos institucionais construídos por pesquisadores dos dois países para possibilitar esse fluxo que, posteriormente, teve continuidade, argumentando que esses se tornaram possíveis pela assimetria entre o estado de autonomização e financiamento da disciplina num e noutro país e, ao mesmo tempo, pela homologia de posições em que se encontravam os pesquisadores brasileiros e argentinos, os primeiros pelo avanço que já tinha a pós-graduação e os segundos pela existência de uma graduação específica em Antropologia, inexistente no Brasil.

Palavras-chave: internacionalização; circulação internacional; mobilidade acadêmica; Museu Nacional; Argentina.
\end{abstract}

\begin{abstract}
How are international circulation flows produced and consolidated in Latin America? As a wide-ranging literature has shown, the international mobility of people is not produced spontaneously, but rather results from a complex social dynamic. This article reconstructs and analyses the processes by which a number of Argentine students were directed to the Postgraduate Program in Social Anthropology of the National Museum (PPGAS-MN), in Rio de Janeiro. Based on the documentary archive of the PPGAS-MN, as well as on interviews with teachers and former students, this study reveals the institutional mechanisms devised by researchers from both countries in order to enable this flow. It is argued that these dynamics were made possible by the asymmetry between the autonomy and financing of the discipline in each country, and at the same time by the homologous positions in which the Brazilian and Argentine researchers found themselves: the former by the advance of the postgraduate degree courses, and the latter by the existence of a graduate degree in Anthropology, which was unavailable in Brazil.
\end{abstract}

Keywords: internationalization; international circulation; academic mobility; National museum; Argentina 
ARGENTINOS A LA BRASILEÑA. LA CIRCULACIÓN DE ANTROPÓLOGOS ARGENTINOS POR EL MUSEU NACIONAL (PPGAS-MN/UFRJ)

\section{Resumen}

¿Cómo se producen y consolidan los flujos de circulación internacional en América Latina? Como ha mostrado una amplia literatura, la circulación internacional de personas no se da de un modo automático, sino que es producto de dinámicas sociales complejas. Este trabajo reconstruye los procesos por los cuales se produjo un flujo de estudiantes argentinos hacia el Programa de Postgrado en Antropología Social del Museo Nacional (PPGAS$\mathrm{MN})$. A partir de un trabajo de archivo en el PPGAS-MN y de entrevistas con profesores y ex estudiantes, el estudio revela los mecanismos institucionales construidos por investigadores de los dos países para posibilitar ese flujo, que tuvo continuidad en el tiempo. Se argumenta que esos mecanismos se tornaron posibles por la asimetría entre el estado de autonomización y financiación de la disciplina en uno y otro país y, al mismo tiempo, por las condiciones en que se encontraban los investigadores brasileños y argentinos, los primeros debido al avance que ya tenía el postgrado, y los segundos por la existencia de una graduación específica en Antropología, inexistente en Brasil.

Palabras clave: internacionalización; circulación internacional; movilidad académica; Museu Nacional; Argentina. 